\title{
Sucrose metabolism in developing oil-rich tubers of Cyperus esculentus: comparative transcriptome analysis
}

\author{
Zhenle Yang ${ }^{1 *}$, Dantong Liu ${ }^{1,2}$ and Hongying $\mathrm{Ji}^{1,2}$
}

\begin{abstract}
Background: Cyperus esculentus is unique in that it can accumulate significant amounts of oil, starch and sugar as major storage reserves in tubers with high tuber yield and therefore considered as a novel model to study carbon allocation into different storage reserves in underground sink tissues such as tubers and roots. Sucrose (Suc) plays a central role in control of carbon flux toward biosynthesis of different storage reserves; however, it remains unclear for the molecular mechanism underlying Suc metabolism in underground oil-rich storage tissues. In the present study, a comprehensive transcriptome analysis of C. esculentus oil tuber compared to other plant oil- or carbohydrate-rich storage tissues was made for the expression patterns of genes related to the Suc metabolism.

Results: The results revealed some species-specific features of gene transcripts in oil tuber of $C$. esculentus, indicating that: (i) the expressions of genes responsible for Suc metabolism are developmentally regulated and displayed a pattern dissimilar to other plant storage tissues; (ii) both of Suc breakdown and biosynthesis processes might be the major pathways associated with Suc metabolism; (iii) it was probably that Suc degradation could be primarily through the action of Suc synthase (SUS) other than invertase (INV) during tuber development. The orthologs of SUS1, SUS3 and SUS4 are the main SUS isoforms catalyzing Suc breakdown while the vacuolar INV (VIN) is the leading determinant controlling sugar composition; (iv) cytosolic hexose phosphorylation possibly relies more on fructose as substrate and uridine diphosphate glucose pyrophosphorylase (UGP) plays an important role in this pathway; (v) it is Suc-phosphate synthase (SPS) B- and C-family members rather than SPS A that are the principal contributors to SPS enzymes and play crucial roles in Suc biosynthesis pathway.

Conclusions: We have successfully identified the Suc metabolic pathways in C. esculentus tubers, highlighting several conserved and distinct expressions that might contribute to sugar accumulation in this unique underground storage tissue. The specific and differential expression genes revealed in this study might indicate the special molecular mechanism and transcriptional regulation of Suc metabolism occurred in oil tubers of C. esculentus.
\end{abstract}

Keywords: Cyperus esculentus, Oil-rich tuber, Sucrose metabolism, Enzymatic pathways, Gene expression pattern

\section{Background}

Cyperus esculentus (commonly known as yellow nutsedge or tiger nut) is a grass-like perennial herb that belongs to the sedge family Cyperaceae that is widely distributed in almost all tropical, subtropical and temperate zones [1]. C. esculentus is currently found a special untraditional underground crop since it has relatively high yield (ranging from 4.5 to $12 \mathrm{t}^{\mathrm{h} \mathrm{h}^{-1} \text { ) [2] }}$

\footnotetext{
*Correspondence: yangzhl@ibcas.ac.cn

${ }^{1}$ Key Lab of Plant Resources, Institute of Botany, Chinese Academy of

Sciences, Beijing 100093, China

Full list of author information is available at the end of the article
}

and its storage tubers accumulate high levels of all three storage reserves: up to $40 \%$ starch, $35 \%$ oil, and $20 \%$ soluble sugars [3-6], which offers it high energy with $400-450 \mathrm{kcal} / 100 \mathrm{~g}$ [6]. Tubers of C. esculentus are edible and consumed in fresh, dried and roasted forms, or milled into flavor gluten-free flour or ground to make a delicious milk-like drink [6,7]. The tubers can be used to produce edible oil which is comparable to olive or hazelnut oils $[8,9]$, and the defatted residue can be further applied for feedstuff or making sugar and brewing wine [10]. In addition, C. esculentus is of great benefit to human health $[11,12]$, and could be utilized as a 
potential good feedstock for biofuel production due to the high contents of oil and starch [13-15].

The accumulation patterns of major storage reserves in developing tubers of $C$. esculentus were previously characterized by biochemical analysis, which indicated that oil, starch and sugars were accumulated in an orderly and gradually way in the developing tubers [4]. Therefore, $C$. esculentus was regarded as a novel model plant to study carbon partitioning into different storage reserves in non-photosynthetic underground storage tissue. However, the molecular mechanism underlying carbon flux allocation of C. esculentus tuber remains unclear.

As an important carbon metabolic process, Suc metabolism is not only crucial for plant growth and development by providing with carbon source and energy [16, 17], but also a determinant for sugar accumulation and pivotal to Suc homeostasis conferring tolerance to biotic and abiotic stresses [18-21]. In particular, Suc metabolism plays a central role in control of carbon flux toward biosynthesis of different storage reserves including starch, oil, sugar, and protein in sink tissues such as seeds, fruits, tubers, stems, bulbs, meristems and flowers [16].

Despite its importance, a description of the comprehensive processes or pathways of Suc metabolism in underground oil-rich storage vegetative tissues is still missing. Although Suc metabolism in model plants is well documented and its process is considered to be a highly conserved among plants, the molecular and biochemical details in oil-rich tuber plants remain elusive. Moreover, the molecular regulatory mechanism underlying Suc metabolism in oil tubers other than oil-rich seeds and fruits, or carbohydrate-rich fruits, roots and tubers is still largely unknown. In this study, we made a comprehensive analysis of the global gene expressions related to Suc metabolism in developing tubers of $C$. esculentus by comparison with other plant oil- or carbohydrate-rich storage organs, and revealed several species-specific gene expression profiles. Our study represents a comprehensive analysis of the genes involved in Suc metabolism in C. esculentus, which will not only shed light on the Suc metabolism in oil tuber tissues, but also provide a foundation for further research on the functions of these genes and subsequent manipulation of Suc metabolism with the aim to increase the accumulation of oil, starch or sugar, as well as the genetic improvement of the quality and yield of C. esculentus tuber.

\section{Results}

\section{Sucrose accumulation in developing tubers of $C$. esculentus}

Compared to other common plants that rich in oil or starch or sugars in their sink organs, the portion of sugars on fresh weight (FW) in mature tubers of C. esculentus is relatively high among the storage reserves, in which it is higher than those of oil plants and even greater than some carbohydrate-rich fruit, root and tuber crops such as grape, sugar beet, sweet potato and potato (Table 1). In tubers of C. esculentus, the major component of sugars is Suc that can accumulate up to $20 \%$ of dry weight, while the minor ones include glucose (Glc) and fructose (Fru) $[4,6,22]$.

To examine the effects of tuber developmental process on sugar accumulation, the sugar contents in developing tubers were determined in this study. The levels of total sugars were calculated as the sum of Suc, Glc, and Fru. The variation of sugar accumulation over the course of nutsedge development spanning around 120 days after seed tuber sowing (DAS) was shown in Fig. 1, which

Table 1 Proximate composition (\% of fresh weight) of plant storage tissues rich in oil or carbohydrate

\begin{tabular}{|c|c|c|c|c|c|c|c|c|}
\hline Plant storage tissues & Plant & Starch & Lipid & Sugars & Protein & Fiber & Moisture & Reference \\
\hline \multirow[t]{6}{*}{ Seed } & Arabidopsis thaliana (Ws) & 0.03 & 36.0 & 2.1 & 30.0 & & 7.0 & {$[23]$} \\
\hline & Rape seed (Brassica napus) & 0.6 & 44.3 & 16.6 & 10.8 & & 5.0 & {$[90]$} \\
\hline & Castor bean (Ricinus communis) & 23.32 & 35.4 & trace & 28.63 & 1.68 & 7.43 & {$[91]$} \\
\hline & Soybean (Glycine max) & 13.53 & 19.94 & 7.33 & 36.49 & 9.3 & 8.54 & [92] \\
\hline & Rice (Oryza sativa) & 78.53 & 0.66 & 0.12 & 7.13 & 1.3 & 11.62 & [92] \\
\hline & Maize (Zea mays) & 10.44 & 1.35 & 6.26 & 3.27 & 2.0 & 76.05 & {$[92]$} \\
\hline \multirow[t]{4}{*}{ Fruit } & Avocado (Persea americana) & 1.54 & 15.41 & 0.3 & 1.96 & 6.8 & 72.33 & [92] \\
\hline & Oil palm (Elaeis guineensis) & 9.8 & 81.9 & 1.0 & 2.2 & 3.8 & trace & {$[92]$} \\
\hline & Date palm (Phoenix dactylifera) & 1.8 & 0.15 & 66.47 & 1.81 & 6.7 & 21.32 & [92] \\
\hline & Grape (Vitis vinifera) & trace & 0.1 & 6.98 & 0.63 & 1.1 & 90.89 & [92] \\
\hline \multirow[t]{2}{*}{ Root } & Sugar beet (Beta vulgaris) & trace & 0.17 & 6.76 & 1.61 & 2.8 & 87.58 & [92] \\
\hline & Sweet Potato (Ipomoea batatas) & 10.29 & 3.88 & 6.63 & 0.66 & 0.88 & 70.54 & {$[93]$} \\
\hline \multirow[t]{2}{*}{ Tuber } & Potato (Solanum tuberosum) & 13.82 & 0.16 & 0.47 & 1.97 & 0.68 & 78.75 & [94] \\
\hline & Tigernut (Cyperus esculentus) & 29.90 & 24.49 & 15.42 & 5.04 & 8.91 & 26.00 & [95] \\
\hline
\end{tabular}



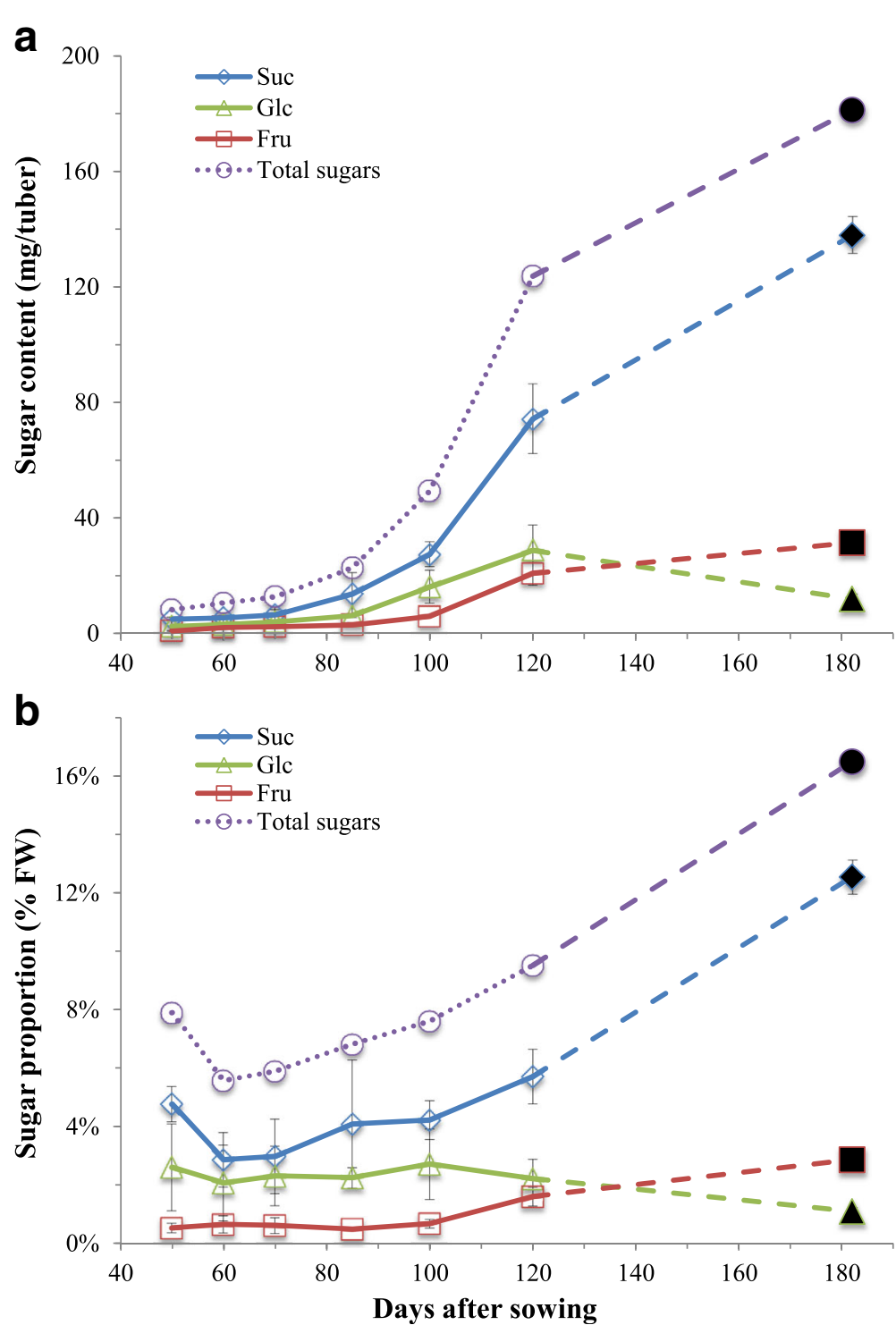

Fig. 1 Percentage of sugars in fresh nutsedge tubers during tuber development. Values represent means $\pm S D(N=5)$. Black solid markers on the right indicate levels of sugars in seed tubers stored for 6 months at $4^{\circ} \mathrm{C}$. $\mathbf{a}$ and $\mathbf{b}$ : Suc, sucrose; Glc, glucose; Fru, fructose. The levels of total sugars were calculated as the sum of Suc, Glc, and Fru

clearly indicated that there were different contents of individual and total sugars at different developmental stages. In all stages of development Suc concentration was highest followed by Glc with Fru being the least abundant. On a per fresh tuber basis, sugar accumulation in tubers was continuous throughout development, where sugar content ranged from 9 to $124 \mathrm{mg} \cdot$ tuber $^{-1}$. There was relatively slow sugar accumulation during early- to mid-stages (40-85 DAS), where the accumulation rate was only $0.41 \mathrm{mg} \cdot$ tuber $^{-1} \cdot \mathrm{d}^{-1}$, much lower than that of late stage (85-120 DAS) with $2.88 \mathrm{mg} \cdot \mathrm{tu}-$ ber $^{-1} \cdot \mathrm{d}^{-1}$, suggesting that there existed differences in the metabolic processes regulating sugar accumulation in developing tubers. At 120 DAS, sugar was increased to $124 \mathrm{mg}$ tuber $^{-1}$, where Suc became much higher than Glc and Fru (Fig. 1a). At this point, sugar represented about $9.5 \%$ of FW, with Suc, Glc and Fru being 5.7, 2.2 and $1.6 \%$, respectively (Fig. 1b). Suc turnover could theoretically generate more Fru over Glc via both INV and SUS catalysis. However, our results showed that Fru remained at lower levels than Glc throughout the tuber development. It was possibly that a higher demand of Fru substrate rather than Glc for hexose metabolism might occur in nutsedge tuber.

The patterns of Suc accumulation in C. esculentus during tuber development were similar to those occurred in developing sink organs for seeds of Arabidopsis [23, 24], rapeseed [25], tobacco [26], soybean [27] and fruits of 
tomato [28], melon [29], apple [30], pineapple [31], peach [32], jackfruit [33], and swelling tuber of potato [34], though the actual Suc contents during Suc accumulation were varying among the different plants. Temporal changes in Suc levels during tuber development clearly indicated that Suc accumulation in C. esculentus is highly regulated by developmental processes, which is likely associated with the expression patterns of Suc metabolism genes.

It was previously demonstrated that Suc accumulation was largely determined by the balance between Suc degradation (INV and SUS activities) and synthesis (SPS activity) [29]. A negative correlation has been observed between Suc accumulation and the activities of INV and SUS [35-37]. Although there remained controversial about the significant correlation with Suc accumulation in the case of SPS activity [35, 36], SPS seemed to play a pivotal role in regulation of Suc mobilization in the cycle of simultaneous Suc degradation and re-synthesis and therefore provide Suc utilization for metabolism [38, 39]. It was suggested that [4], when developing tuber of $C$. esculentus were transformed from cell-division into storage compartments where oil accumulation was commenced, there was a switch of main enzyme activity from INV to SUS-mediated Suc metabolism, leading to a shift from high hexose-to-Suc to high Suc-to-hexose in tubers. In this study, we indeed observed the high Suc-to-hexose ratios over the tuber development of $C$. esculentus (Fig. 1), where oil accumulation began at around 50 DAS [40].

Overall, our results revealed that the changes in sugar accumulation were associated with the tuber development.

\section{Sucrose metabolism-related genes in C. esculentus tubers display different transcriptional patterns from those of other plant oil-rich or carbohydrate-rich storage tissues} Our previous transcriptome analyses of $C$. esculentus tubers from three representative samples at 50, 85 and 120 DAS of developmental stages (i.e. the early stage of 40-50 DAS, the middle stage of 50-85 DAS and the late stage of 85-120 DAS, corresponding to the stage of low oil level and oil accumulation rate, medium oil level but high oil accumulation rate, and high oil level with low oil accumulation rate, respectively) have indicated that $41.05 \%$ of total 99,558 transcripts were successfully annotated [40]. Among them, 488 annotated transcripts were involved in carbohydrate metabolism, of which 355 unigenes were found to be expressed in the developing C. esculentus tubers (Additional file 1: Table S1d). More than 120 transcripts and 60 unigenes were identified for Suc metabolism (Additional file 1: Table S3). The majority of the Suc metabolism-related transcripts and unigenes were involved in hexose phosphorylation, followed by Suc degradation and Suc synthesis in this order (Fig. 2b,
Additional file 1: Table S1d). Most of already known Suc metabolism enzymes and/or proteins were successfully detectable in tubers of C. esculentus, indicating their ability to participate in Suc metabolism in oil tubers, as similar to other plants.

Based on the gene expression of our transcriptome data and current model of plant Suc metabolism, the core Suc metabolic ways in $C$. esculentus tuber were illustrated in Fig. 2a. Suc metabolism primarily comprises of three metabolic pathways, i.e., Suc breakdown, phosphorylation of hexoses including Glc and Fru, and biosynthetic reactions of Suc from phosphorylated hexoses. Suc breakdown in the non-photosynthetic sink tissues involves two ways, hydrolysis and cleavage by various enzymes. Suc unloaded from the phloem may enter either apoplasmically into cell wall matrix or taken up intact symplasmically through plasmodesmata (PD) [41, 42], thus Suc can be either hydrolyzed by cell wall invertases (CWINs) into of its constituent monosaccharides such as Glc and Fru, or degraded by SUS into UDP-Glc and Fru, or by intracellular invertases such as cytoplasm invertases (CINs) and VINs, producing Glc and Fru [17]. Hexose phosphorylation mainly involves multiple pathways in which the resulting Glc, Fru and UDP-Glc are phosphorylated to glucose-6-phsophate (G6P), fructose-6-phosphate (F6P) and glucose-1-phsophate (G1P) by hexokinase (HXK), fructose-specific fructokinase (FK) and UGP, respectively. The reversible conversion of G6P into F6P or G1P is catalyzed by phosphoglucoisomerase (PGI) or phosphoglucomutase (PGM). Suc re-synthesis primarily involves two-step irreversible reactions where F6P combined with UDP-Glc is converted into Suc-6-phosphate (S6P) through the action of SPS, and subsequently S6P is converted into Suc and phosphate catalyzed by S6P phosphatase (SPP) [43].

In $C$. esculentus, the expressions of genes related to Suc synthesis among these metabolic pathways were most abundant, with an average value of transcript levels, represented by FPKM (fragments per kilobase of exon model per million mapped reads) per protein, almost equaling the total levels of Suc degradation and hexose phosphorylation (Fig. 2b). This result suggested that transcriptional regulation of Suc synthesis might be a major factor associated with Suc metabolism in $C$. esculentus tuber.

In addition, genes expressed in the three metabolic processes were all down-regulated across the tuber development, with different transcript levels at various stages of development (Fig. 3b), suggesting that genes associated with Suc metabolism in C. esculentus tuber are developmentally regulated. This is further confirmed by the results of quantitative realtime PCR (qRT-PCR) analysis for selected candidate genes associated with Suc metabolism in developing tubers (Fig. 4). 


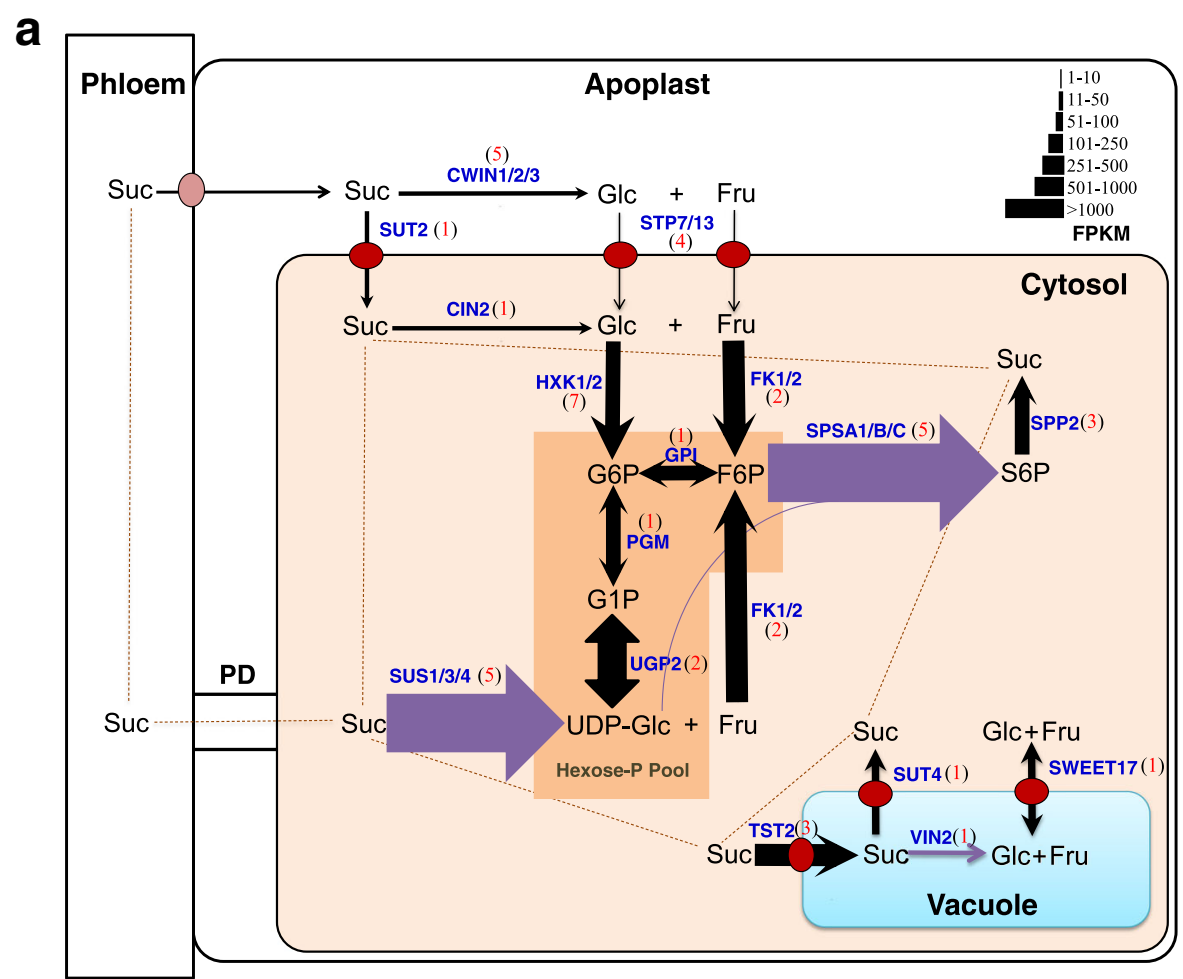

b
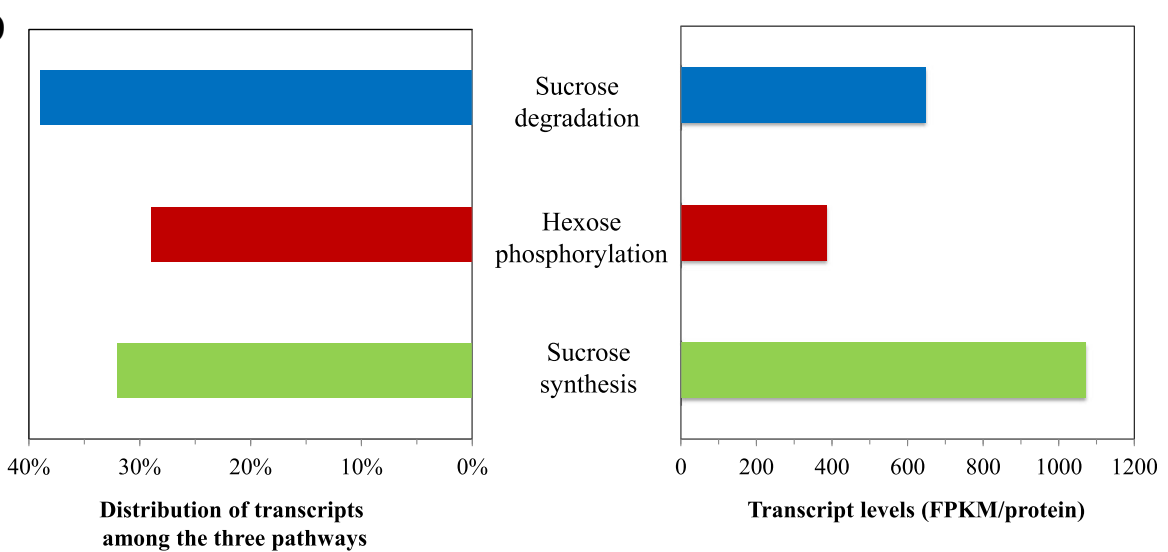

Fig. 2 Gene expression pattern for Suc metabolism. a Schematic Suc metabolic pathways in oil-rich tubers of Cyperus esculentus. Enzyme or protein names are indicated in blue. For each enzyme or protein, the width of the arrow indicates the gene expression level (FPKM, average fragments per kilobase of exon model per million mapped reads). Black and purple arrows indicate respectively the common and different gene expression patterns in Cyperus esculentus tuber from those in other plant examined in this study. Transporter was marked by the black arrow across red oval. FPKM values of the different isoforms and/or subunits are average transcript levels. Red numbers in black bracket show the numbers of unigenes with more than 1 of FPKM for each enzyme or protein. Abbreviation: CIN, cytoplasmic invertase; CWIN, cell wall invertase; F6P, fructose-6-phosphate; FK, fructokinase; Fru, fructose; G1P, glucose-1-phosphate; G6P, glucose-6phosphate; Glc, glucose; Hexose-P, hexose-phosphate; HT, hexose transporter; HXK, hexokinase; PD, plasmodesmata; PGl, phosphoglucoisomerase; PGM, phosphoglucomutase; S6P, succose-6-phosphate; SPP, sucrose-phosphatase.; SPS, sucrose-phosphate synthase; Suc, sucrose; SUS, sucrose synthase; SUT, sucrose transporter; T6P, trehalose-6-phosphate; TPS, trehalose-6-phosphate synthase; TST, tonoplast sucrose transporter; SWEET, Sugars Will Eventually be Exported Transporter (hexose and sucrose transporter); UDP-Glc, uridine diphosphate glucose; UGP, UDP-Glc pyrophosphorylase; VIN, vacuolar invertase. $\mathbf{b}$ Expression levels for Suc metabolism genes. Left, The distribution of transcript contents among the three pathways. Right, FPKM per protein in each pathway. Without regard to separation of close paralogs or allelic transcripts, multiple protein isoforms or subunits of a multiprotein complex were considered as a single protein and their transcripts were summed (Additional file 1: Table S3) 
A

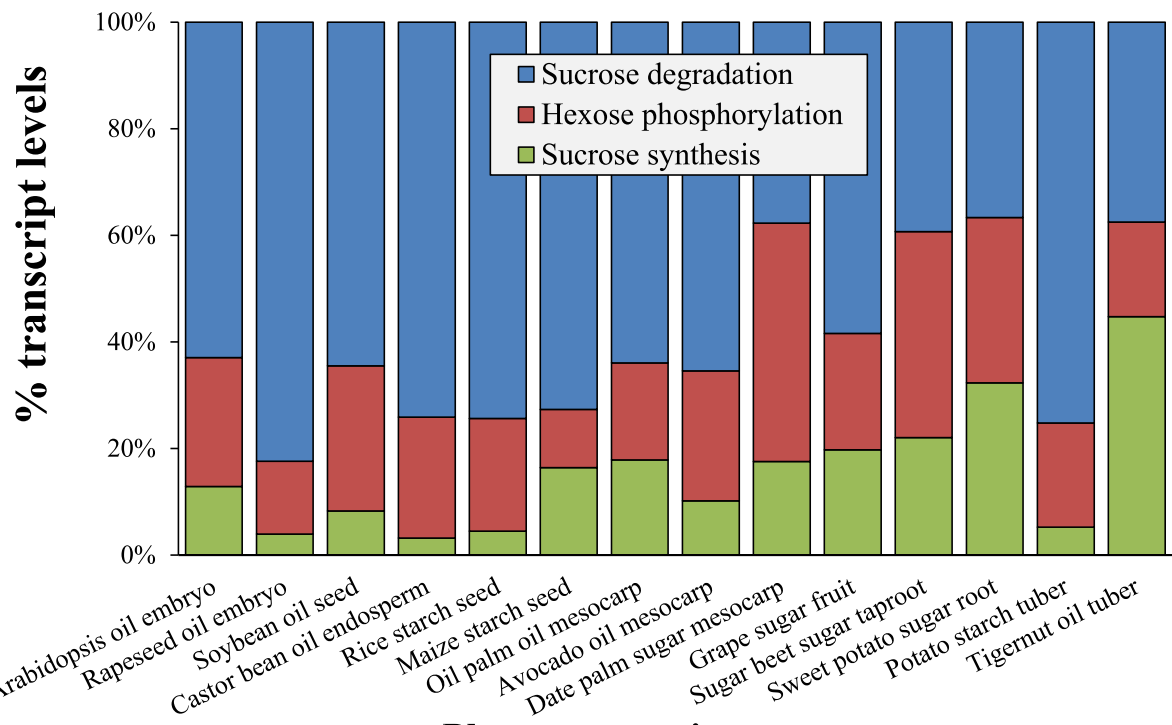

B

Plant storage tissues

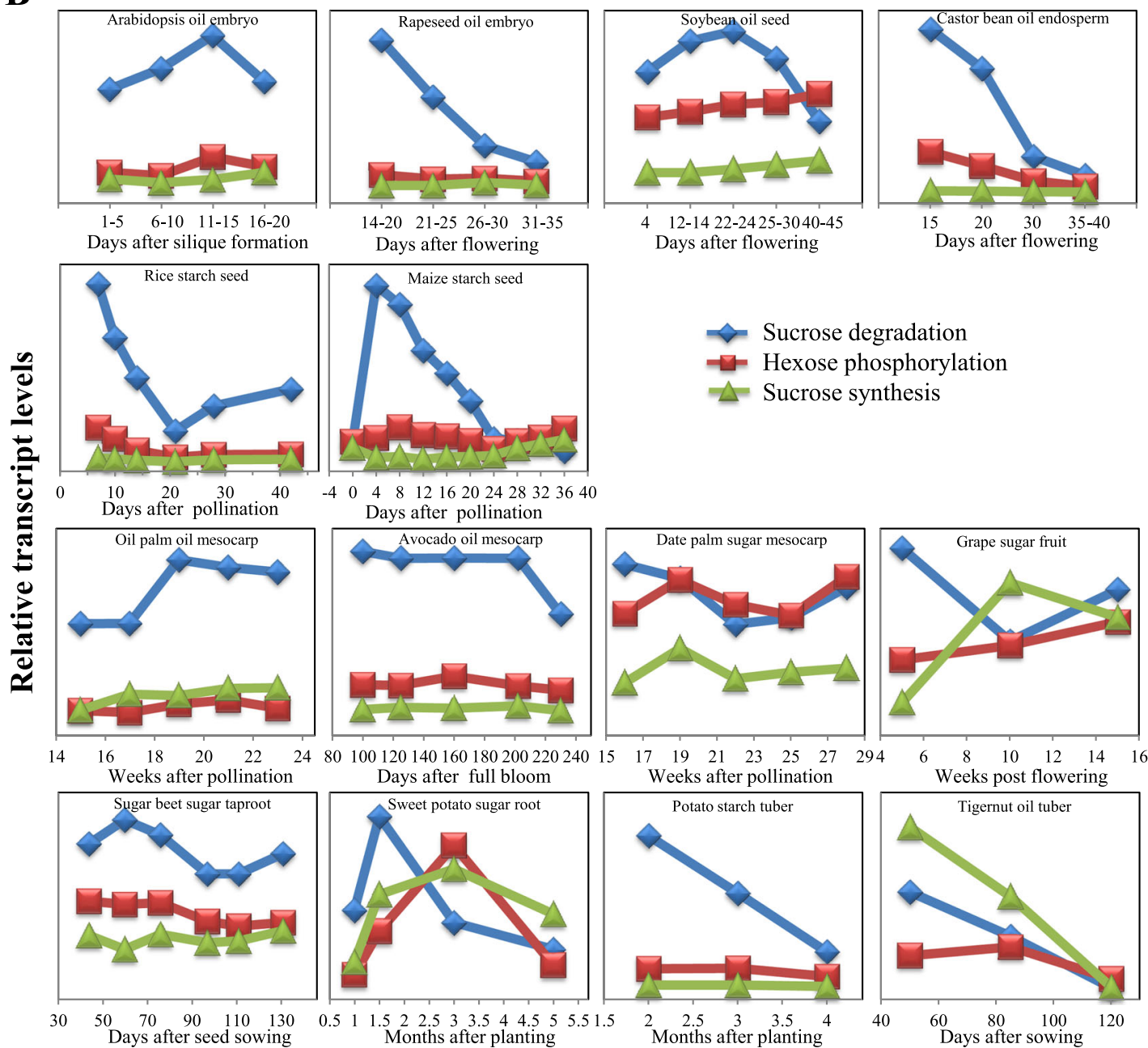

Fig. 3 (See legend on next page.) 
(See figure on previous page.)

Fig. 3 Expression patterns for three metabolic pathways of Suc metabolism in diverse plant storage tissues. a The relative distribution of transcripts among the selected three pathways related to Suc metabolism in diverse plant storage tissues. The data are averaged on all developing stages of plant tissues. b Temporal transcriptional levels during plant development. Transcriptome data of diverse plants are based on: (1) seeds of Arabidopsis [85], rapeseed [86], soybean [68], castor bean [86], rice [69], and maize [70]; (2) fruits of oil and date palm ([87], avocado [88], and grape [89]; (3) roots of sugar beet [67] and sweet potato [57]; and (4) tubers of potato [56] and tigernut (this study)

We found that, the Suc metabolism in C. esculentus tubers had different transcriptional patterns from those of other plant storage tissues such as oil-rich or carbohydrate-rich seeds, fruits, roots and tubers (Fig. 3). In contrast to $C$. esculentus tuber, the most highly expressed genes in other plant species were involved in Suc degradation, rather than Suc synthesis. Furthermore, the transcripts for Suc synthesis were much lower, with a 2- to 30-fold less than the total levels of Suc degradation and hexose phosphorylation (Fig. 3a). In addition, the temporal expression patterns of Suc metabolism were also dissimilar between $C$. esculentus tuber and other plant storage tissues during the course of development (Fig. 3b). In C. esculentus tuber, transcripts for the three Suc metabolic pathways were all down-regulated, and in particular, both of Suc degradation and synthesis

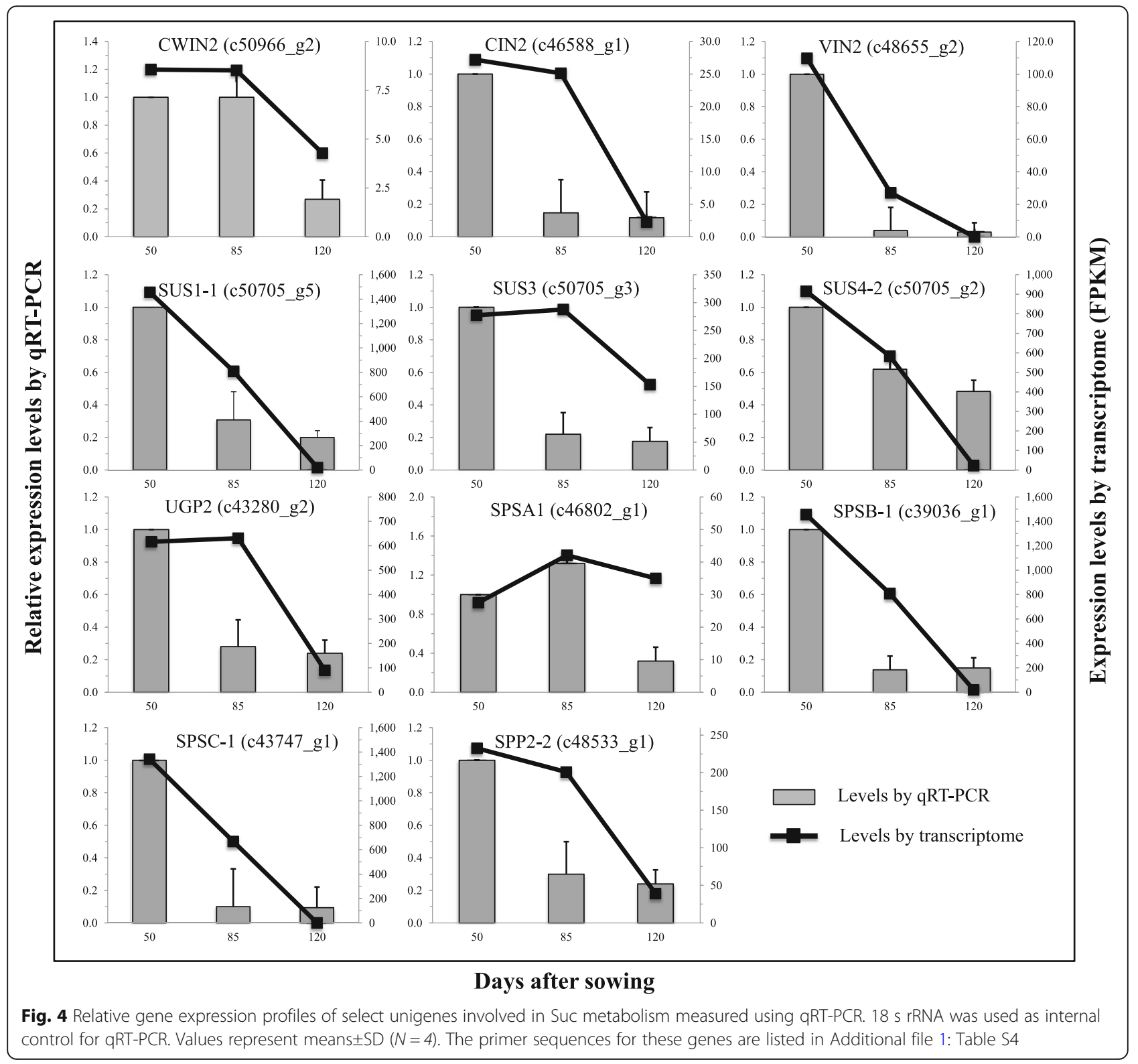


displayed coordinated temporal expression during tuber development. In contrast, Suc synthesis genes in other plant storage tissues were expressed constantly or slightly up and showed a different pattern from those of Suc degradation across all the developmental stages.

Together, our data indicated that the genes related to Suc metabolic pathways in C. esculentus tubers have distinct transcriptional patterns from those of other plant oil-rich or carbohydrate-rich storage tissues, indicating a different regulation of gene expression present in $C$. esculentus tubers.

\section{Sucrose synthase transcripts are highly expressed during sucrose degradation in C. esculentus tubers}

Before it is channeled into various pathways in different subcellular compartments, Suc must be either hydrolyzed irreversibly by INV into Glc and Fru, or converted reversibly but preferably cleaved with UDP into UDP-Glc and Fru catalyzed by SUS [44] (Fig. 2a).

In $C$. esculentus tuber, the transcripts for the SUS genes in the cytosol were highly expressed, having a transcript value of more than $2500 \mathrm{FPKM}$ /protein on average (Additional file 1: Table S3). The abundant expression levels of SUS, which were at least 10-fold higher than $I N V$, also occurred across all the tuber development (Fig. 5). Much higher expression of SUS over INV in oil tuber is similar to other plant storage organs (Fig. 6a), indicating a conserved function of SUS in Suc metabolism among diverse plant storage tissues. In addition, our data showed that the change trend in transcripts for SUS genes in tuber development was negatively correlated with the variations in Suc contents, further supporting the important role of SUS in Suc degradation. These data suggest that SUS might be the preferred enzyme for initial Suc metabolism and the intracellular Suc degradation is likely to primarily rely on the activity of SUS with high levels of transcripts in tubers of $C$. esculentus. Our results could reinforce and support the enzyme assays of seeds of rapeseed, wheat, lima bean, and tuber of potato which indicated that SUS predominated over INV in enzyme activity during the storage organ development and is the major enzyme responsible for hexose generation [45-48]. It was demonstrated that SUS plays a physiologically important role as a key enzyme involved in Suc metabolism that appears to be largely in charge of channeling photoassimilated carbon into sink organs and its sucrolysis is the primary entry route of carbon from Suc [49].

It was shown that SUS is encoded by a small multigene family that comprises at least two isoforms in most plant species, with the number of isoforms varying in different plant species. For example, Arabidopsis and rice contain six distinct $S U S$ genes $[50,51]$, while there are three SUS genes in maize and pea $[52,53]$. In $C$. esculentus tuber, four isoforms of SUS orthologs were identified, including one copy of SUS3 (AT4G02280) and SUS6 (AT1G73370), two copies of SUS1 (AT5G20830) and SUS4 (AT3G43190) (Additional file 1: Table S3). Among these isoforms, the most transcribed one is the SUS1 ortholog, which is followed by SUS4 and SUS3, while SUS6 was only faintly expressed (Fig. 5). During the tuber development, the three SUS1, SUS3 and

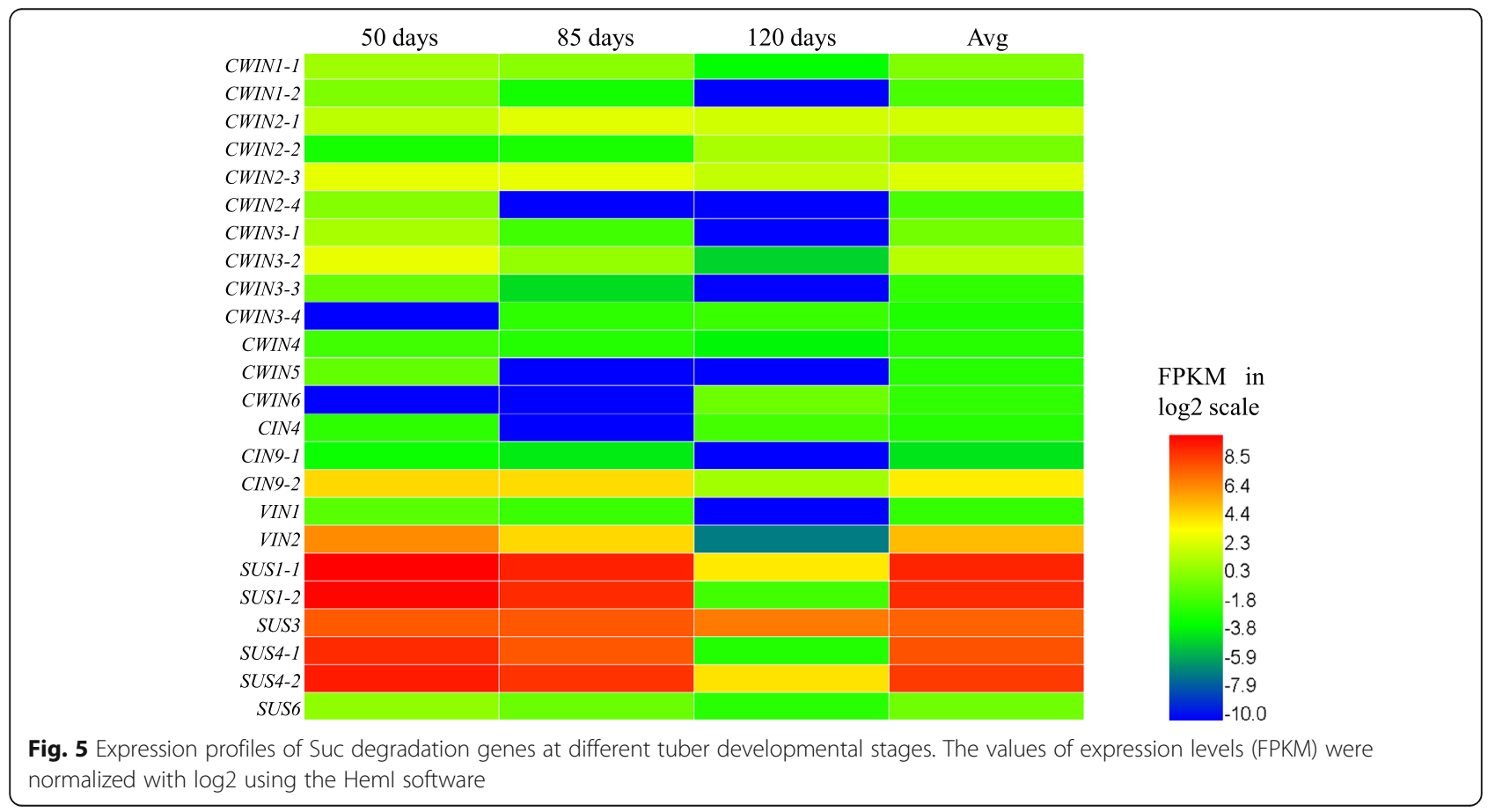




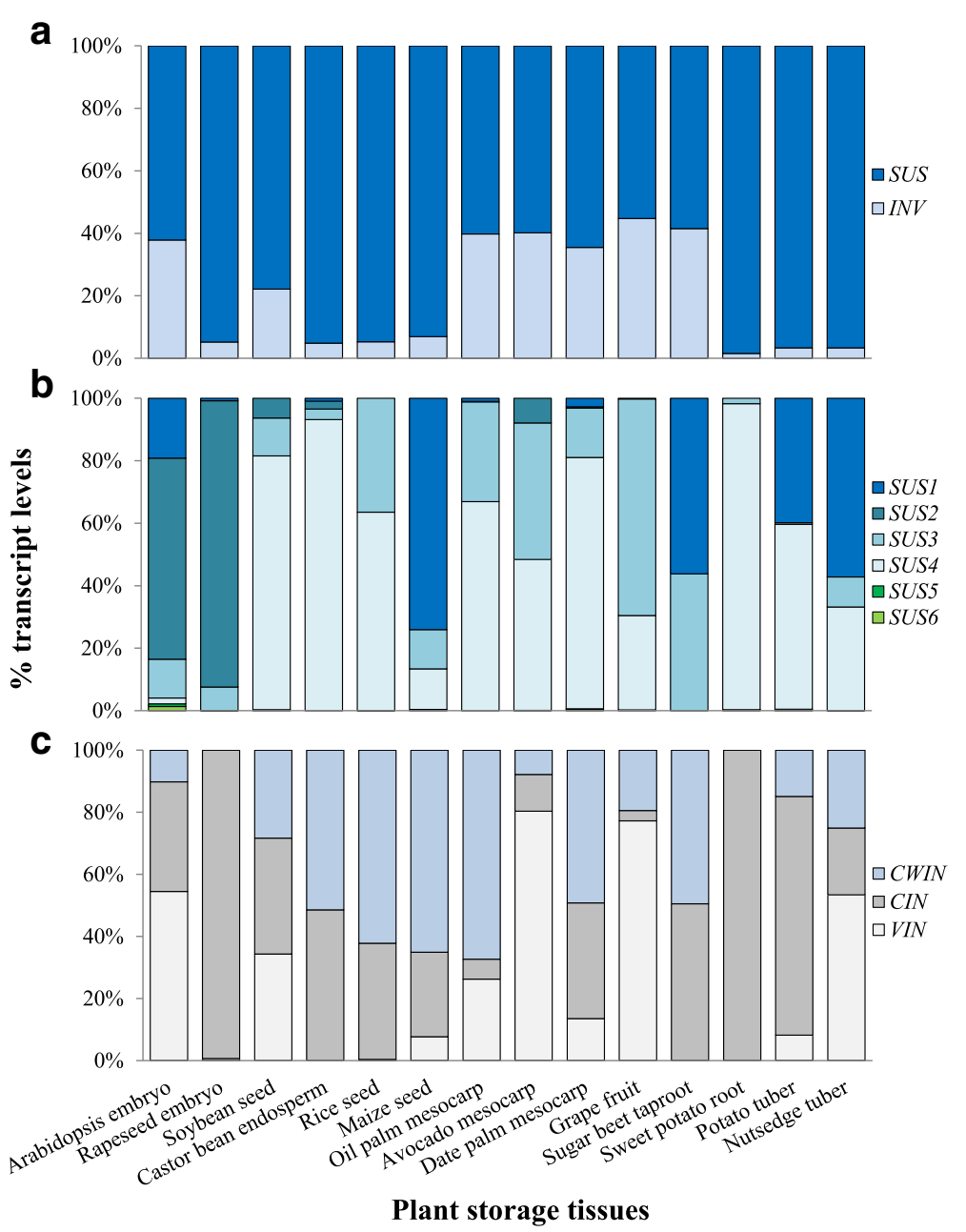

Fig. 6 Expression patterns of Suc degradation genes in diverse plant storage tissues. a The relative distribution of transcripts of SUS over INV. $\mathbf{b}$ The relative distribution of transcripts of SUS isoforms. c The relative distribution of transcripts of INV isoforms

SUS4 orthologs were all down-regulated and showed a coordinated expression pattern (Fig. 5), implying the important contribution of these SUS isoforms to Suc synthase. The relative high transcript levels of SUS1 in C. esculentus tuber were not common to other plant storage tissues. For example, abundantly expressed SUS1 were only identified in seeds of Arabidopsis and maize, sugarbeet taproot and potato tuber (Fig. 6b). The results of phylogenetic analyses also suggest that the expression pattern of SUS1 in C. esculentus tuber is specific (Fig. 7a).

The existence and relative high abundance of transcripts for the orthologs of SUS3 and SUS4 also occurred in other plant seeds, fruits, roots and tubers, implying an evolutionarily conserved role for these two isoforms of SUS enzyme in Suc degradation among diverse plant storage tissues. In contrast to most seed and fruit tissues, SUS2 ortholog was either not found or were barely detectable in C. esculentus tuber, similar to roots of sugar beet and sweet potato as well as potato tuber, suggesting that ortholog of SUS2 is not a prerequisite for Suc synthase in root and tuber tissues, and perhaps SUS2 ortholog in seed and fruit tissues may have evolved to play an additional role in Suc breakdown. The absence and/or very weak expression of SUS5 and SUS6 suggested their less contribution to Suc synthase in various sink organs of diverse plants.

Overall, these results strongly indicated that the SUS genes in C. esculentus tuber displayed specific temporal and spatial expression patterns. It is likely that different isoforms of Suc synthase could have particular functions in the tuber. Previous evidence has shown that the members of Arabidopsis SUS genes exhibited partially overlapping but also different expression features. AtSUS2 was highly and specifically expressed only in the developing seeds; in contrast, AtSUS1, AtSUS5 and AtSUS6 were more generally expressed in the root, stem, flower, siliques and seed. AtSUS3 is mainly expressed in the root, flower and seed [49]. 
a

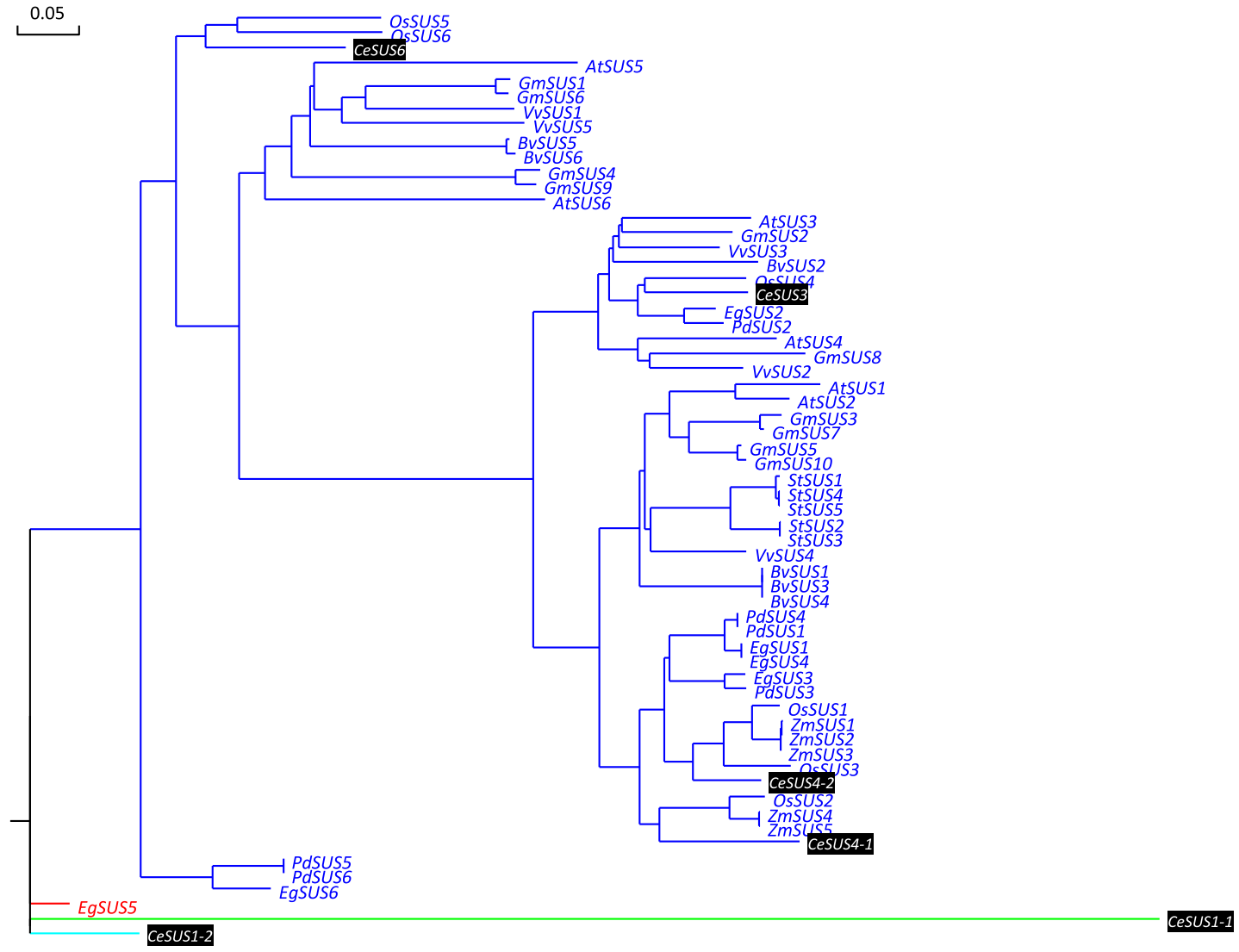

b

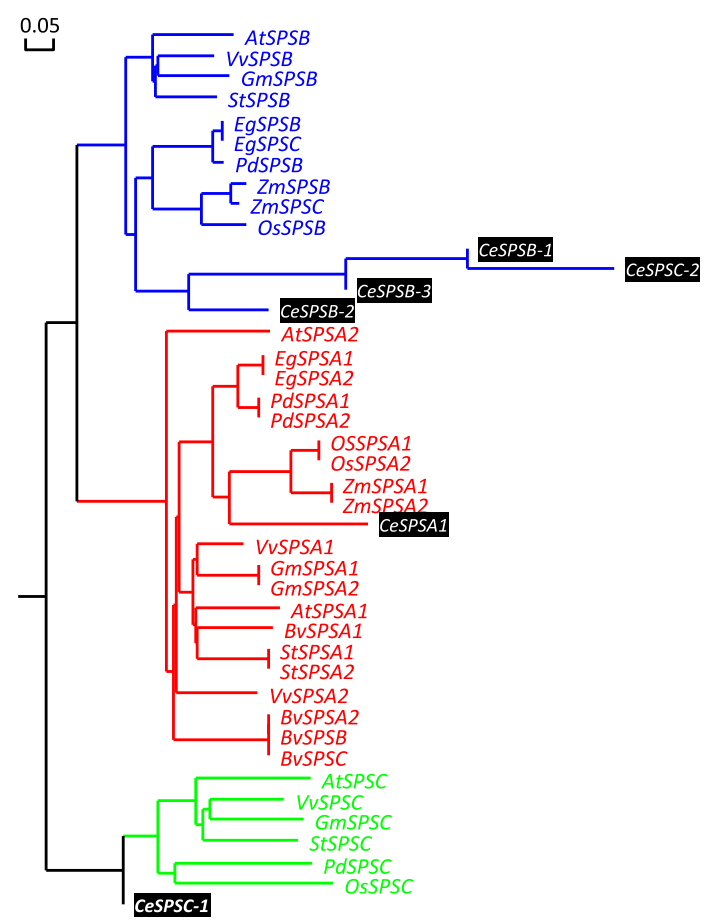

Fig. 7 (See legend on next page.) 
(See figure on previous page.)

Fig. 7 Phylogenetic trees for (a) SUS and (b) SPS gene subfamilies among diverse plants. Trees were constructed by using the Maximum

Likelihood method based on the Jones-Taylor-Thornton (JTT) matrix-based model. These trees were constructed based on amino acid sequences. Phylogenetic analyses were conducted in DNAMAN8. At, Arabidopsis thaliana; Gm, Glycine max; St, Solanum tuberosum; Vv,Vitis vinifera; Os, Oryza sativa; Zm, Zea mays; Eg, Elaeis guineensis; Pd, Phoenix dactylifera; Bv, Beta vulgaris; Ce, Cyperus esculentus

The expression patterns of invertase genes are speciesspecific in $C$. esculentus tubers

INV is usually categorized into three sub-families based on the subcellular localization, i.e., cell wall INV (CWIN), vacuolar INV (VIN), and cytosolic INV (CIN) which may also be expressed in plastids, mitochondria and nuclei $[17,43,54]$.

The three types of INV genes were also detectable in C. esculentus tuber, but their transcript expressions were relative low as compared to SUS, no more than 120 FPKM even at early tuber development, and decreased to less than 15 FPKM at tuber maturity (Fig. 5). Among these INV orthologs, more than $50 \%$ of the transcripts were contributed by the VIN isoforms, while CWIN and $C I N$ orthologs were represented by 25 and $22 \%$, respectively (Fig. 6c). The very low expression for $C W I N$ in oil tubers might reflect the availability of hexoses for cytosol is primarily through CIN or SUS or both catalytic reactions. This is further supported by the expression patterns of hexose transporters (HTs), where HTs were only poorly expressed that had less than 15 FPKM of transcripts which were seven-fold on average lower than Suc transporters (SUTS) (Additional file 1: Table S3). Suc transport in C. esculentus tuber was believed to be similar to potato [4]. When tuberization was initiated, Suc was unloaded symplastically from the phloem through plasmodesmata [55].

The transcript expressions and their contribution of the three subcellular INVS in nutsedge were quite different from the counterparts in other plant storage organs, which were varied across the species and tissues (Additional file 2: Figure S1). This is confirmed by the fact that none of the plant storage tissues examined in this study has the same ratio of isoenzymes or transcript patterns as seen in other plants. For example, in underground storage tissues, the highest expression in sweet potato and potato was for the CIN orthologs rather than $V I N$, in contrast to nutsedge with the transcripts for VIN being the richest. The CIN2 isoform transcribed most abundantly in potato, but it was absent in sweet potato and nutsedge. Seven isoforms of CWIN orthologs (CWIN1-6) were detectable in C. esculentus, while only CWIN1 and CWIN3 orthologs were expressed with low transcripts in potato [56], and no CWINs were identified in sweet potato [57].

The multiplicity of genes and the high divergence in expression patterns in the $I N V$ subfamilies among diverse plants may reflect the evolution of mechanisms underlying the Suc hydrolysis catalyzed by INVs. It was demonstrated that INV gene duplication and divergence occurred prior to the separation of the plant species during evolution [58]. This divergence supports the hypothesis that the various INV genes have specialized functions [54]. Their expressions were characterized by tissue-, organelle- and development-specific expression patterns $[59,60]$. The physiological advantage of having multiple isoenzymes of INVs might be a greater flexibility in the control of Suc metabolism, translocation or storage under different conditions [59].

The differentially regulated expression of $I N V$ orthologs was also observed in the development of oil tubers of C. esculentus. As shown in Fig. 5, the three INV subfamilies displayed distinct expression patterns, though they were all down-regulated across the tuber development. VIN orthologs had the most abundant transcripts with over 3-fold higher than CWIN or CIN at early stage of tuber development, but they were hardly expressed at tuber maturity. At tuber mid-stage development, these $I N V s$ were almost equally transcribed. All these facts reflect that the three INV isoforms are developmentally regulated and expressed with overlapping but distinct expression patterns. It might indicate that Suc partitioning via Suc turnover in developing C. esculentus tubers could be that SUS would regulate Suc utilization, whereas isoenzymes of INV control Suc storage and sugar composition, as pointed out by previous studies $[20,58,61,62]$. The plant vacuole is the major site for sugar storage and plays a central role in the temporary or long-term storage of sugars [63]. A positive correlation of VIN activity with hexose accumulation has been found in tomato, grape berry and potato tubers [64-66].

\section{Cytosolic hexose phosphorylation in C. esculentus tubers display distinct and conserved expression patterns}

The hexose phosphorylation is related to the synthesis of F6P toward Suc synthesis via three different pathways catalyzed by various enzymes (Fig. 2a). One is the direct conversion of Fru to F6P by the action of FK. The other one is involved in the formation of G6P from Glc catalyzed by HXK and the subsequent conversion of G6P to F6P through the reversible catalytic action of GPI. The third one is through the way that G1P is produced from UDP-Glc and then converted into G6P, which were catalyzed by UGP and PGM, respectively $[17,43]$.

C. esculentus tuber contained all of the five enzymes necessary for the hexose phosphorylation, as other plant 
storage tissues (Fig. 8), except for the sugar beet taproot where UGP was not detected at gene expression levels [67]. However, the distribution of transcript levels of the orthologs of the five gene family members was varying in different tissues and in diverse species. In C. esculentus tuber, the expression level of UGP was highest, which was followed by $P G M$ and then $F K$, while the $H X K$ and GPI were the least. Such an expression pattern is quite different from other plants, indicating that the hexose phosphorylation process in different plants is possibly dominated by different enzymes.

In most plant species, each of the five enzymes for hexose phosphate pathway was encoded more than one gene. As shown in Additional file 3: Figure S2, the transcripts for isoforms of the same gene family were contributed in great difference in different plant tissues, showing the dissimilarities of expression patterns of gene isoforms among diverse plant species. Most plants contain two isoforms of UGP or PGM, whereas in C. esculentus tuber only one isoform of UGP2 or PGM2 ortholog was identified. In contrast to most plant tissues having single copy of $U G P 2$, four copies of $U G P 2$ ortho$\log$ were detected in C. esculentus tuber (Additional file 1: Table S3), comparable to the seeds of soybean [68], rice [69], and maize [70] which have three or four UGP2 isoforms.

A comparison of the transcripts of the orthologs of each gene family in diverse tissues of plants indicated the dissimilarities, while also revealed several conserved features. As in most plant tissues, the higher abundance of transcript level for $F K$ orthologs than that of $H X K$ was also observed in nutsedge tuber, suggesting that the hexose phosphorylation perhaps relies primarily on Fru substrate. In addition, the more abundance of transcripts

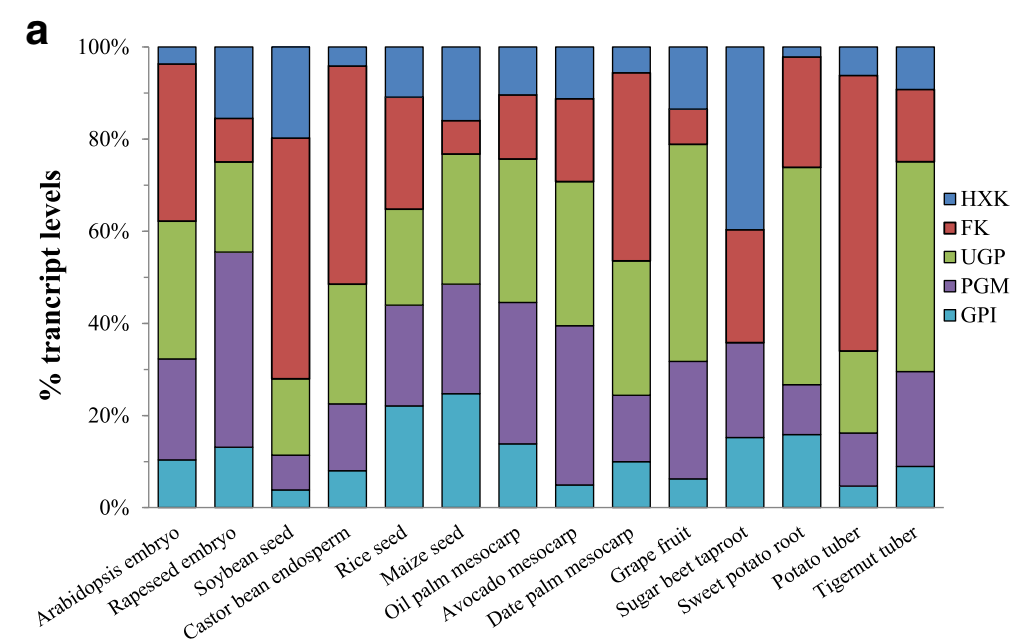

b

Plant storage tissues

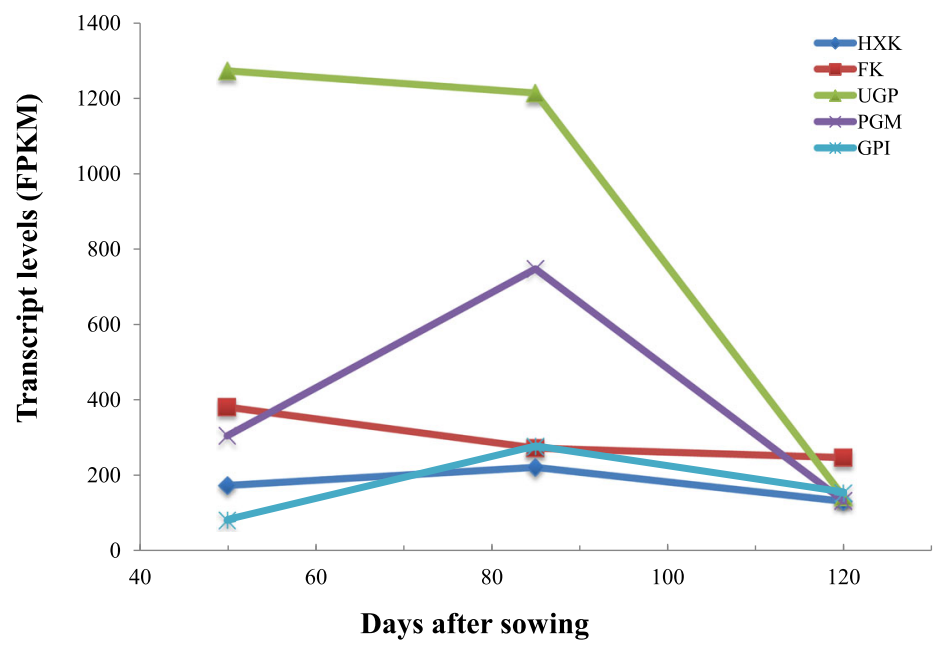

Fig. 8 Expression patterns of each hexose phosphorylation genes in diverse plant storage tissues. The relative distribution of transcript levels in different plant storage tissues. a The transcript levels (FPKM) are average values and summed for subunits of a protein and for multiple isoforms. b Temporal transcriptional levels in developing tuber of $C$. esculentus 
for UGP and PGM orthologs than $H X K$, along with much higher expression levels for SUS than INV implicated that UGP-mediated G6P synthesis is highly active and UGP might be the major determinant in generation of G6P and play an important role in hexose phosphate pathways.

It was observed that during oil tuber development, the five enzyme genes displayed distinct expression patterns (Fig. 8b), indicating that their expressions were developmentally regulated. Furthermore, the expression patterns were not consistent with the changes in Suc contents, suggesting that these enzymes might not be the major factors associated with Suc accumulation in C. esculentus tuber.

\section{Gene expressions of Suc biosynthetic pathway in oil tubers of $C$. esculentus may be atypical}

The production of Suc in the pathway of Suc biosynthesis starting from UDP-Glc in combination with F6P generally involves two enzymes: SPS and SPP (Fig. 2a). SPS catalyzes the formation of S6P from UDP-Glc and F6P, whereas SPP catalyzes the irreversible hydrolysis of S6P to generate Suc. The SPP catalytic reaction is basically irreversible and changes the equilibrium of reversible SPS reaction toward the direction of net Suc synthesis [17].

In nutsedge tuber, the orthologs of Suc biosynthesis genes were represented by an average of 1070 FPKM/ protein (Fig. 2b). More than $90 \%$ of the transcripts encoding for Suc biosynthesis proteins were attributed by SPS orthologs (Fig. 9a). Similar higher expression levels for SPS, relative to SPP, were also observed in other oilor carbohydrate-rich plant tissues except for Arabidopsis seed and avocado mesocarp where SPS were expressed slightly less than SPP. However, the highly expressed patterns of SPS in C. esculentus tuber presented a striking contrast to those of most of other plant tissues in which the SPS orthologs were expressed with less five-fold higher as compared to $S P P$, whereas the transcript levels for SPS in C. esculentus tuber were more ten-fold than that of $S P P$, similar to the case in date palm mesocarp or potato tuber.

The higher expression of SPS than SPP ortholog in $C$. esculentus tuber also occurred in the course of tuber development (Fig. 9b). Both of SPS and SPP orthologs were expressed in a down-regulation way. At the early stage, the transcripts for SPS were much more abundant, at least 15 -fold higher than those for SPP. Even at tuber maturity, although the expression levels for SPS and SPP
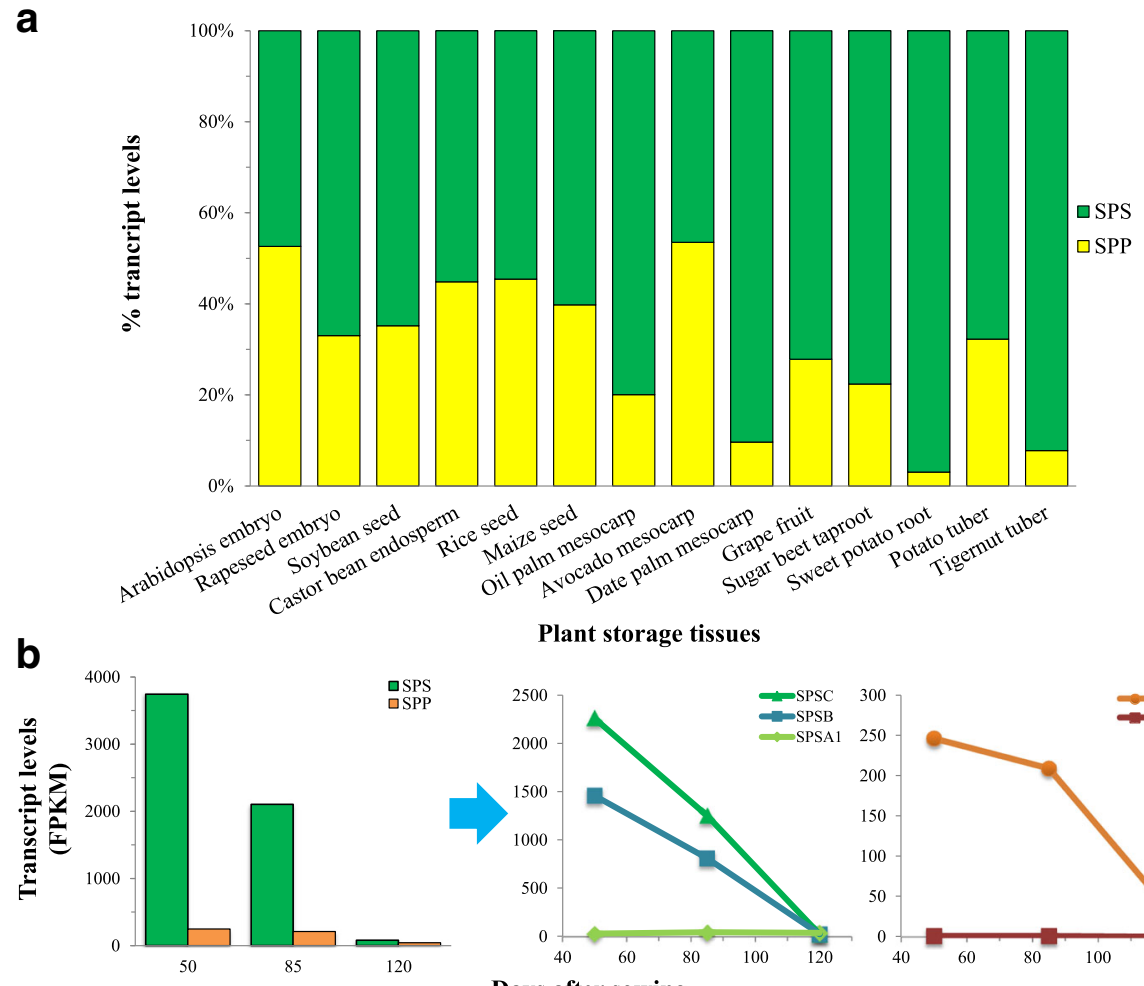

Plant storage tissues

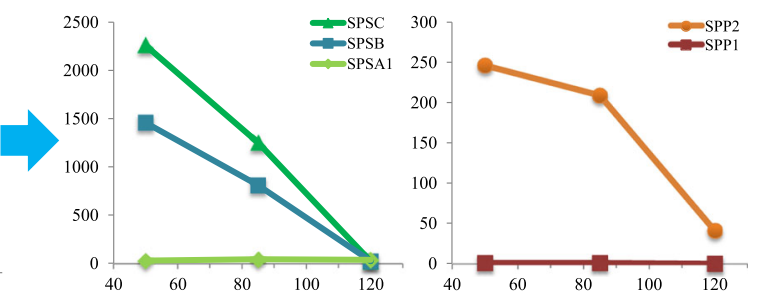

Days after sowing

Fig. 9 Expression patterns of sucrose phosphate synthase (SPS) gene and sucrose phosphate phosphatase (SPP) gene. a The relative distribution of transcript levels in different plant storage tissues. b Temporal transcriptional levels for SPS and SPP in developing tuber of C. esculentus 
declined by more forty- and six-fold, respectively, the expression level of SPS remained two-fold higher than that of $S P P$.

Overall, these results above may reflect the predominant role of SPS ortholog played in Suc synthesis in $C$. esculentus tuber, supporting the fact that SPS is a key regulatory enzyme in the pathway of Suc synthesis and makes a significant contribution to control the flux of carbon into Suc [71, 72], while SPP seems to have little control over carbon flux toward Suc biosynthesis [73].

Evidence has shown that higher plants contain several SPS isoforms encoded by a small SPS multigene family. In Arabidopsis, SPS gene family consists of four member isoforms which are denoted as SPSA1 (AT5G20280), SPSA2 (AT5G11110), SPSB (AT1G04920) and SPSC (AT4G10120) [74-76]. In nutsedge tuber, the SPSA2 ortholog was not identified (Additional file 4: Figure S3). The transcripts for the ortholog of SPSC were the most abundant, followed by SPSB. SPSA1 was least expressed, with only $2 \%$ of total transcripts among SPS isoforms. The relative low expressions of SPSA isoforms in C. esculentus tuber may reflect their less contribution to SPS enzyme responsible for Suc synthesis. These results were in stark contrast to the observations made in other plant storage tissues, where SPSA were most abundantly expressed while $S P S B$ and SPSC were poorly transcribed or undetectable (Additional file 4: Figure S3). The difference in SUS gene subfamilies between $C$. esculentus and other plants was also suggested by the phylogenetic analyses (Fig. 7b). It has been reported that Arabidopsis SPSA1 and SPSA2 were expressed in all organs $[75,77,78]$, while $S P S B$ was mainly expressed in the reproductive organs, and the $S P S C$ gene was preferentially expressed in leaves, indicating that SPSA- and $C$-family members were the major SPS isoforms expressed in leaves, which seems to be the same thing for Arabidopsis seeds (Additional file 4: Figure S3). It is noted that SPSA1 was expressed in all of plant storage tissues examined, though to a different extent. Previous phylogenetic analyses revealed that the regulatory phosphorylation sites of SPS are well conserved among SPSA family members from different species [77], suggesting that the SPSA isoforms, in particularly SPSA1, were evolutionary conservation and might play a housekeeping role in plants.

The temporal expression patterns of the three SPS genes in C. esculentus tubers also revealed that SPSBand $C$-family members constitute the major $S P S$ isoforms expressed (Fig. 9b), in which they were all transcribed and appear to be enzymatically active during the tuber development. However, gene expression of SPSA1 was slightly up-regulated, while the transcripts for the SPSB and SPSC isoforms showed down-regulation patterns which were in accordance with the dynamic changes in Suc contents. It may reflect that SPSA1 appear to be functionally distinct, at least in part, from $S P S B$ - and $C$-family members in C. esculentus tubers and not crucial for Suc synthesis.

The role of SPP in Suc synthesis and whether SPP is or not rate limiting still remain elusive. It was previously demonstrated that SPP seems to make less contribution to the control of Suc biosynthesis [73]. In Arabidopsis, four copies of SPP genes, SPP1 (At1g51420), SPP2 (At2g35840), SPP3A (At3g54270) and SPP3B (At3g5 2340) (Additional file 4: Figure S3), have a similar exon-intron structure [74, 79]. In C. esculentus tubers, $S P P$ family comprises four genes with one copy of SPP1 and three copies of SPP2 orthologs, without SPP3 members (Additional file 1: Table S3). They displayed distinct expression profiles where the expression levels for SPP2 isoform were more 100-fold higher than SPP1. SPP1 was expressed very weakly across the tuber development (Fig. 9b). The dominant expression patterns for SPP2 isoform also occurred in other plant storage tissues (Additional file 4: Figure S3), implicating the evolutionary conservation and a housekeeping role in diverse plants for SPP2 ortholog. These results reinforce and extend to a recent study revealing that Arabidopsis SPP2 was expressed most abundantly and showed the highest activity in aerial parts of the plant, whereas SPP1 isoform was a non-active enzyme gene and mainly expressed in roots [80].

\section{Discussion}

In contrast to common tuber and root crops such as potato and carrot which exclusively accumulate carbohydrates as the major storage components, $C$. esculentus is a currently known only plant that produces tubers containing high amounts of both oil and starch as main storage reserves. Furthermore, C. esculentus also accumulate a significant amount of sugars in tubers. Thus, $C$. esculentus is considered a novel model plant suitable for studying carbon partitioning toward the biosynthesis of various storage reserves in underground sink tissues such as tubers and roots [4]. In this study, we have carried out for the first time comprehensive transcriptome analyses of gene expressions related to Suc metabolism, a central reaction for various carbon metabolism, from Suc degradation toward Suc re-synthesis in C. esculentus tubers, and compared with other plant oil- or carbohydrate-rich storage tissues including seeds, fruits, roots, and tubers so as to disclose the underlying mechanism of Suc metabolism in oil tuber plants.

Our results showed that gene isoforms involved in conventional Suc metabolic pathways consisting of consecutive reactions of Suc breakdown, hexose phosphorylation and Suc re-biosynthesis are also present in $C$. esculentus tuber and they are functionally conserved among diverse plant species, indicating that plant sink 
tissues remain a common set of gene isoforms for Suc metabolism during plant evolution. As other plant oilor carbohydrate-rich sink tissues, the expressions of genes responsible for Suc metabolism in C. esculentus tuber appear to be developmentally regulated. The higher levels of transcripts of Suc degradation over hexose phosphorylation in C. esculentus tuber are also similar to those of oil- or carbohydrate-rich storage tissues. Similarly, in both C. esculentus tuber and other plant storage tissues are shown much higher transcript levels for SUS than INV isoforms and for SPS against SPP genes. In addition, multiple temporal expression patterns of genes involved in hexose phosphate pathways also occur in diverse plant storage tissues, suggesting the relative importance of these different enzymes during plant development.

Nevertheless, there are several distinct gene expression patterns that are likely to be tissue or species specific in C. esculentus tuber. In contrast to other plant storage organs, C. esculentus had high abundance of gene expressions in its tuber for both Suc degradation and synthesis that displayed a coordinated temporal expression pattern in agreement with the changes in Suc levels during tuber development. Therefore, the oil tuber of C. esculentus could be used to explore mechanisms modulating the net flux through the Suc pool regulated by the cycle of simultaneous degradation and synthesis of Suc, and whether it is a prerequisite or not to maintain a high net rate of Suc degradation during tuber development. In this respective, given only the orthologs for SUS1, SUS3 and SUS4 among SUS isoforms were highly expressed in a similar pattern in tubers, this oleaginous tissue is suitable to determine the significance of the simultaneous expression of these three SUS isoforms and to examine the possibility of their overlapping function in catalyzing Suc breakdown. In striking contrast to other plant storage organs, the orthologs for SPSB and SPSC isoforms, where their function in Suc biosynthesis is still not well understood in model plants, were abundantly transcribed with a coordinated expression pattern in C. esculentus tuber. Thus, the oil-rich tuber of C. esculentus could serve as an ideal system to characterize the specific functions and regulation for these two SPS isoforms in Suc biosynthesis. With the poor expression or absence of vacuolar INVS in common belowground crops such as roots of sugar beet and sweet potato, as well tuber of potato, it remains elusive as to how individual VIN isoforms modulate vacuolar sugar homeostasis, cytosolic hexose levels and cell expansion in underground storage tissues; however, the identification of VIN2 ortholog with relative abundant transcripts among VINs in nutsedge tuber provides with an useful means to study the function and regulation of VIN2 isoform and the mechanisms underlying VIN-mediated plant development.

\section{Conclusion}

In conclusion, our comprehensive transcriptome analysis of oil tuber of C. esculentus in comparison with other plant oil- or carbohydrate-rich storage tissues showed Suc metabolism genes with both similar and different species-specific expression patterns, pointing to the fact that in C. esculentus, (i) Suc metabolism also occurs across the tuber development of $C$. esculentus and the transcriptional expressions of the related genes are highly developmentally regulated; (ii) most of Suc metabolism genes are present with multiple isoforms as well, most likely to fulfill their diverse functions in the control of Suc metabolism under different conditions; (3) genes for both Suc degradation and re-synthesis are highly expressed with a coordinated downregulation pattern, dissimilar to the case in other plant storage tissues; and (4) the orthologs of SUS1, INV2, UGP2, SPSB, and $S P S C$ having relatively abundant transcript levels in $C$. esculentus tuber could be potential gene targets for future metabolic engineering approaches. Together, our study gives insights into the transcriptional control of Suc metabolism in the developing oil tuber tissues. Such knowledge has implications for manipulating potential targets for Suc metabolism in C. esculentus through metabolic engineering or molecular breeding to promote this underutilized crop large-scale cultivation and utilization to improve the biomass quantity and quality of $C$. esculentus tuber.

\section{Methods \\ Plant materials}

Cyperus esculentus L. var. sativus were grown in an incubator at $22 \pm 0.5^{\circ} \mathrm{C}, 40-60 \%$ relative humidity and $16 \mathrm{~h}$ light $\left(130 \mu \mathrm{mol} \cdot \mathrm{m}^{2} \cdot \mathrm{s}^{-1}\right) / 8 \mathrm{~h}$ dark cycle. Fresh tubers were harvested at different developmental stages and stored in liquid nitrogen immediately until further use.

\section{Sugar determination}

At least 10 tubers were pooled and ground in liquid $\mathrm{N}_{2}$ into fine powder that was then homogenized in $80 \%(\mathrm{v} / \mathrm{v})$ ethanol for $5 \mathrm{~min}$. After that, the homogenate was centrifuged at $6000 \mathrm{~g}$ for $10 \mathrm{~min}$ and the liquid supernatant was used for sugar analysis. Quantification of soluble sugars (Suc, Glc, and Fru) in tubers was determined using anthrone colorimetric method of Morris [81] in combination with the 3, 5-dinitro salicylate method of Miller [82].

\section{Total RNA extraction}

Total RNA was isolated from the developing tubers using a modified cetyltrimethylammonium bromide (CTAB)-based method as described in detail in [40]. Pure RNA sample was dissolved in RNase-free water and stored in liquid nitrogen. 


\section{RNA deep sequencing}

The quality and yield of total RNAs were verified using a NanoDrop 2000 spectrophotometer and an Agilent 2100 Bioanalyzer. RNA sequencing was performed using the Illumina Hiseq4000 sequencing platform (Shanghai Major Biomedicine Technology Co. Ltd., China). RNA-seq data are available on the National Center for Biotechnology Information (NCBI) Short Read Archive ProjectPRJNA320781, PRJNA320787 and PRJNA312713. Annotation for De novo assembly sequences (>200 bp) was conducted using a BLAST homology search against the NCBI protein database (ftp://ftp.ncbi.nlm.nih.gov/blast/ $\mathrm{db} /$ ), Swiss-Prot (http://www.ebi.ac.uk/uniprot/), COG (http://www.ncbi.nlm.nih.gov/COG/), STRING (http:// string-db.org/), GO (http://www.geneontology.org/) and KEGG (http://www.genome.jp/kegg/). The levels of gene expressions were quantified using fragments per kilobase of exon model per million mapped reads (FPKM) [83].

\section{Quantitative real-time PCR (qRT-PCR) analysis}

qRT-PCR analysis was carried out with SYBR Green Realtime PCR Master Mix (Toyobo Co. Ltd.) using the system of Eppendorf Mastercycler ep realplex (Eppendorf Company, Germany), as the method in our previous work [40]. Relative mRNA was quantified by the $\Delta \Delta \mathrm{C}_{\mathrm{T}}$ method [84]. 18S rRNA was used as the internal control. Primer pairs for qRT-PCR analysis were listed in Additional file 1: Table S4.

\section{Additional files}

Additional file 1: Table S1. Summary of C. esculentus transcriptome datasets, assembly and annotation, and number of transcripts and unigenes related to carbohydrate metabolism. Table S2. Annotation of C. esculentus transcriptome. Table S3. Annotation and expression levels for selected genes associated with sucrose metabolism. Table S4. Primer pairs used for QRT-PCR. Table S5. The assembled sequences for selected genes associated with sucrose metabolism. (XLSX 6684 kb)

Additional file 2: Figure S1. Relative gene expression levels for each invertase isoform in diverse plant storage tissues. (PDF $86 \mathrm{~kb}$ )

Additional file 3: Figure S2. Relative gene expression levels for each isoform of hexose phosphorylation in diverse plant storage tissues. (PDF $63 \mathrm{~kb}$ )

Additional file 4: Figure S3. Relative gene expression levels for each isoform of sucrose synthesis pathways in diverse plant storage tissues. (PDF $61 \mathrm{~kb}$ )

\footnotetext{
Abbreviations

CIN: cytoplasmic invertase; CWIN: cell wall invertase; F6P: fructose-6phosphate; FK: fructokinase; Fru: fructose; G1P: glucose-1-phosphate; G6P: glucose-6-phosphate; Glc: glucose; Hexose-P: hexose-phosphate; HT: hexose transporter; HXK: hexokinase; PD: plasmodesmata; PGI: phosphoglucoisomerase; PGM: phosphoglucomutase; S6P: succose-6phosphate; SPP: Suc-phosphatase; SPS: Suc-phosphate synthase; Suc: Suc; SUS: Suc synthase; SUT: Suc transporter; SWEET: Sugars Will Eventually be Exported Transporter (hexose and Suc transporter); T6P: trehalose-6phosphate; TPS: trehalose-6-phosphate synthase; TST: tonoplast Suc transporter; UDP-Glc: uridine diphosphate glucose; UGP: UDP-Glc pyrophosphorylase; VIN: vacuolar invertase
}

\section{Acknowledgements}

We are greatly grateful to Dr. Xing Deng from our institute for qRT-PCR technical assistance.

\section{Funding}

This work was supported by Beijing Natural Science Foundation (No. 5151001) and the National Natural Science Foundation of China (No. 31371692).

\section{Availability of data and materials}

RNA-seq data are available on NCBI Short Read Archive ProjectPRJNA320781, PRJNA320787 and PRJNA312713. All data generated or analyzed during this study are included in this published article and its additional files.

\section{Authors' contributions}

ZY designed research. ZY, DL and HJ conducted experiments. ZY analyzed data and prepared the manuscript. All authors read and approved the final manuscript.

\section{Ethics approval and consent to participate}

Not applicable.

\section{Consent for publication}

Not applicable.

\section{Competing interests}

The authors declare that they have no competing interests.

\section{Publisher's Note}

Springer Nature remains neutral with regard to jurisdictional claims in published maps and institutional affiliations.

\section{Author details}

${ }^{1}$ Key Lab of Plant Resources, Institute of Botany, Chinese Academy of Sciences, Beijing 100093, China. ${ }^{2}$ University of Chinese Academy of Sciences, Beijing 100049, China.

Received: 11 October 2017 Accepted: 5 July 2018

Published online: 24 July 2018

\section{References}

1. De Castro O, Gargiulo R, De Guacchio E, Caputo P, De Luca P. A molecular survey concerning the origin of Cyperus esculentus (Cyperaceae, Poales): two sides of the same coin (weed vs. crop). Ann Bot. 2015;115(5):733-45.

2. Makareviciene V, Gumbyte M, Yuni A, Kalenska kS, Kalenski V, Rachmetov D, Sendzikiene E. Opportunities for the use of chufa sedge in biodiesel production. Ind Crop Prod. 2013;50:633-7.

3. Arafat S, Gaafar A, Basuny A, Nassef L. Chufa tubers (Cyperus esculentus L.): as a new source of food. World Appl Sci J. 2009;7:151-6.

4. Turesson H, Marttila S, Gustavsson KE, Hofvander P, Olsson ME, Bülow L, Stymne S, Carlsson AS. Characterization of oil and starch accumulation in tubers of Cyperus esculentus var. sativus (Cyperaceae): a novel model system to study oil reserves in nonseed tissues. Amer J Bot. 2010;97:1884-93.

5. Sanchez-Zapata E, Fernandez-Lopez J, Perez-Alvarez JA. Tiger nut (Cyperus esculentus) commercialization: health aspects, composition, properties, and food applications. Compr Rev Food Sci Food Safe. 2012;11:366-77.

6. Codina-Torrella I, Guamis B, Trujillo AJ. Characterization and comparison of tiger nuts (Cyperus esculentus L.) from different geographical origin: Physicochemical characteristics and protein fractionation. Ind Crop Prod. 2015;65: 406-14.

7. Belewu MA, Belewu KY. Comparative physico-chemical evaluation of tigernut, soybean and coconut milk sources. Int J Agric Biol. 2007;9:785-7.

8. Dubois V, Breton S, Linder M, Fanni J, Parmentier M. Fatty acid profiles of 80 vegetable oils with regard to their nutritional potential. Eur J Lipid Sci Technol. 2007;109:710-32.

9. Ezeh O, Gordon MH, Niranjan K. Tiger nut oil (Cyperus esculentus L.): a review of its composition and physico-chemical properties. Eur J Lipid Sci Technol. 2014;116:783-94.

10. Duan J, Ma J. Tiger nut cultivation (in Chinese). Beijing: Popular Science Press; 1983. 
11. Bamishaiye El, Bamishaiye OM. Tiger nut: as a plant, its derivatives and benefits. Afri J Food Agri Nutr Dev. 2011;11:5157-70.

12. Defelice MS. Yellow nutsedge Cyperus esculentus L.- - snack food of the gods. Weed Technol. 2002;16:901-7.

13. Zhang HY, Hanna MA, Ali Y, Nan L. Yellow nutsedge (Cyperus esculentus L.) tuber oil as fuel. Ind Crop Prod. 1996;5:177-81

14. Barminas JT, Maina HM, Tahir S, Kubmarawa D, Tsware K. A preliminary investigation into biofuel characteristics of tigernut (Cyperus esculentus) oil. Bioresour Technol. 2001;79:87-89.

15. Ofoefule $\mathrm{AU}$, Ibeto $\mathrm{CN}$, Okoro UC, Onukwuli OD. Biodiesel production from tigernut (Cyperus esculentus) oil and characterization of its blend with petrodiesel. Phys Rev Res Inter. 2013;3:145-53.

16. Lunn JE. Sucrose Metabolism. eLS. 2008; https://doi.org/10.1002/ 9780470015902.a0021259.

17. Ruan Y-L. Sucrose metabolism: gateway to diverse carbon use and sugar signaling. Annu Rev Plant Biol. 2014;65:33-67.

18. Herbers K, Meuwly P, Frommer WB, Metraux JP, Sonnewald U. Systemic acquired resistance mediated by the ectopic expression of invertase: possible hexose sensing in the secretory pathway. Plant Cell. 1996;8:793803.

19. Bonfig KB, Gablera A, Simon UK, Luschin-Ebengreuth N, Hatzc M, Berger S, Muhammad N, Zeier J, Sinha AK, Roitsch T. Post-translational derepression of invertase activity in source leaves via down-regulation of invertase inhibitor expression is part of the plant defense response. Mol Plant. 2010;3: 1037-48.

20. Ruan Y-L, Jin Y, Yang YJ, Li GJ, Boyer JS. Sugar input, metabolism, and signaling mediated by invertase: roles in development, yield potential, and response to drought and heat. Mol Plant. 2010;3:942-55.

21. Xiang L, Le Roy K, Bolouri-Moghaddam M-R, Vanhaecke M, Lammens W, Rolland $F$, Van den Ende W. Exploring the neutral invertase-oxidative stress defence connection in Arabidopsis thaliana. J Exp Bot. 2011;62:3849-62.

22. Linssen JPH, Cozijnsen JL, Pilnik W. Chufa (Cyperus esculentus): a new source of dietary fibre. J Sci Food Agri. 1989;49:291-6.

23. Baud S, Boutin JP, Miquel M, Lepiniec L, Rochat C. An integrated overview of seed development in Arabidopsis thaliana ecotype WS. Plant Physiol Biochem. 2002;40:151-60.

24. Focks N, Benning C. wrinkled1: a novel, low-seed-oil mutant of Arabidopsis with a deficiency in the seed-specific regulation of carbohydrate metabolism. Plant Physiol. 1998;1 18:91-101.

25. Hill LM, Morley-Smith ER, Rawsthorne S. Metabolism of sugars in the endosperm of developing seeds of oilseed rape. Plant Physiol. 2003;131: 228-36.

26. Tomlinson KL, McHugh S, Labbe H, Grainger JL, James LE, Pomeroy KM, Mullin JW, Miller SS, Dennis DT, Miki BL. Evidence that the hexose-tosucrose ratio does not control the switch to storage product accumulation in oilseeds: analysis of tobacco seed development and effects of overexpressing apoplastic invertase. J Exp Bot. 2004;55:2291-303.

27. Saldivar $X$, Wang $Y$, Chen $P$, Hou A. Changes in chemical composition during soybean seed development. Food Chem. 2011;124:1369-75.

28. Klann EM, Chetelat RT, Bennett AB. Expression of acid invertase gene controls sugar composition in tomato (Lycopersicon) fruit. Plant Physiol. 1993;103:863-70

29. Hubbard NL, Pharr DM, Huber SC. Sucrose phosphate synthase and acid invertase as determinants of sucrose concentration in developing muskmelon (Cucumis melo L.) fruits. Plant Physiol. 1989:91:1527-34.

30. Li M, Feng F, Cheng L. Expression patterns of genes involved in sugar metabolism and accumulation during apple fruit development. PLoS One. 2012;:e33055

31. Zhang XM, Wang W, Du LQ, Xie JH, Yao YL, Sun GM. Expression patterns, activities and carbohydrate-metabolizing regulation of sucrose phosphate synthase, sucrose synthase and neutral invertase in pineapple fruit during development and ripening. Int J Mol Sci. 2012;13:9460-77.

32. Desnoues E, Gibon Y, Baldazzi V, Signoret V, Génard M, Quilot-Turion B. Profiling sugar metabolism during fruit development in a peach progeny with different fructose-to-glucose ratios. BMC Plant Biol. 2014;14:336.

33. Hu L, Wu G, Hao C, Yu H, Tan L. Transcriptome and selected metabolite analyses reveal points of sugar metabolism in jackfruit (Artocarpus heterophyllus lam.). Plant Sci. 2016;248:45-56.

34. Ross HA, Davies HV, Burch LR, Viola R, McRae D. Developmental changes in carbohydrate content and sucrose degrading enzymes in tuberising stolons of potato (Solanum tuberosum). Physiol Plant. 1994;90:748-56.
35. Miron D, Schaffer AA. Sucrose phosphate synthase, sucrose synthase and acid invertase activities in developing tomato fruit of Lycopersicon escufenfum mill. And sucrose accumulating Lycopersicon hirsutum Humb. and Bonpl. Plant Physiol. 1991;95:624-7.

36. Islam S, Matsui T, Yoshida Y. Carbohydrate content and the activities of sucrose synthase, sucrose phosphate synthase and acid invertase in different tomato cultivars during fruit development. Sci Hortic. 1996;65:125-36.

37. Yativ $\mathrm{M}$, Hararya I, Wolf $\mathrm{S}$. Sucrose accumulation in watermelon fruits: genetic variation and biochemical analysis. J Plant Physiol. 2010;167:589-96.

38. Dali N, Michaud D, Yelle S. Evidence for the involvement of sucrose phosphate synthase in the pathway of sugar accumulation in sucroseaccumulating tomato fruits. Plant Physiol. 1992;99:434-8.

39. Geigenberger P, Reimholz R, Deiting U, Sonnewald U, Stitt M. Decreased expression of sucrose phosphate synthase strongly inhibits the water stressinduced synthesis of sucrose in growing potato tubers. Plant J. 1999;19:119-29.

40. Yang Z, Ji H, Liu D. Oil biosynthesis in underground oil-rich storage vegetative tissue: comparison of Cyperus esculentus tuber with oil seeds and fruits. Plant Cell Physiol. 2016;57:2519-40.

41. Riesmeier JW, Willmitzer L, Frommer WB. Evidence for an essential role of the sucrose transporter in phloem loading and assimilate partitioning. EMBO J. 1994:13:1-7.

42. Patrick JW. Does don Fisher's high-pressure manifold model account for phloem transport and resource partitioning? Front Plant Sci. 2013;4:184.

43. Lunn JE. Sucrose Metabolism. eLS. 2016; https://doi.org/10.1002/ 9780470015902.a0021259.pub2.

44. Koch K. Sucrose metabolism: regulatory mechanisms and pivotal roles in sugar sensing and plant development. Current Opin in Plant Biol. 2004;7: 235-46.

45. Xu DP, Sung SJ, Black CC. Sucrose metabolism in lima bean seeds. Plant Physiol. 1989;89(4):1106-16.

46. Riffkin $\mathrm{HL}$, Duffus $\mathrm{CM}$, Bridges IC. Sucrose metabolism during endosperm development in wheat (Triticum aestivum). Physiol Plant. 1995;93(1):123-31.

47. Appeldoorn NJG, De Bruijn SM, Koot-Gronsveld EAM, Visser RGF, Vreugdenhil D, Van Der Plas LHW. Developmental changes of enzymes involved in conversion of sucrose to hexose-phosphate during early tuberisation of potato. Planta. 1997:202:220-6.

48. Morley-Smith ER, Pike MJ, Findlay K, Kockenberger W, Hill LM, Smith AM, Rawsthorne $S$. The transport of sugars to developing embryos is not via the bulk endosperm in oilseed rape seeds. Plant Physiol. 2008;147:2121-30.

49. Bieniawska Z, Paul Barratt DH, Garlick AP, Thole V, Kruger NJ, Martin C, Zrenner R, Smith AM. Analysis of the sucrose synthase gene family in Arabidopsis. Plant J. 2007:49:810-28.

50. Baud S, Vaultier MN, Rochat C. Structure and expression profile of the sucrose synthase multigene family in Arabidopsis. J Exp Bot. 2004;55(396): 397-409.

51. Hirose T, Scofield GN, Terao T. An expression analysis profile for the entire sucrose synthase gene family in rice. Plant Sci. 2008;174:534-43.

52. Barratt DH, Barber L, Kruger NJ, Smith AM, Wang TL, Martin C. Multiple, distinct isoforms of sucrose synthase in pea. Plant Physiol. 2001;127:655-64.

53. Duncan KA, Hardin SC, Huber SC. The three maize sucrose synthase isoforms differ in distribution, localization, and phosphorylation. Plant Cell Physiol. 2006;47:959-71.

54. Sturm A. Invertases. Primary structures, functions, and roles in plant development and sucrose partitioning. Plant Physiol. 1999;121(1):1-8.

55. Viola R, Roberts AG, Haupt S, Gazzani S, Hancock RD, Marmiroli N, Machray GC, Oparka KJ. Tuberization in potato involves a switch from apoplastic to symplastic phloem unloading. Plant Cell. 2001;13(2):385-98.

56. Hofvander P, Ischebeck T, Turesson H, Kushwaha SK, Feussner I, Carlsson AS, Andersson M. Potato tuber expression of Arabidopsis WRINKLED1 increase triacylglycerol and membrane lipids while affecting central carbohydrate metabolism. Plant Biotechnol J. 2016;14:1883-98.

57. Tao X, Gu YH, Wang HY, Zheng W, Li X, Zhao CW, Zhang YZ. Digital gene expression analysis based on integrated de novo transcriptome assembly of sweet potato [/pomoea batatas (L.) lam]. PLoS One. 2012;7:e36234.

58. Fridman E, Zamir D. Functional divergence of a syntenic invertase gene family in tomato, potato, and Arabidopsis. Plant Physiol. 2003;131(2):603-9.

59. Tymowska-Lalanne Z, Kreis M. The plant invertases: physiology, biochemistry and molecular biology. Adv Bot Res. 1998;28:71-117.

60. Sturm A, Tang GQ. The sucrose-cleaving enzymes of plants are crucial for development, growth and carbon partitioning. Trends Plant Sci. 1999:4(10): 401-7. 
61. Sturm A. Molecular characterization and functional analysis of sucrosecleaving enzymes in carrot (Daucus carota L.). J Exp Bot. 1996;47:1187-92.

62. Tang $\mathrm{GQ}$, Sturm A. Antisense repression of sucrose synthase in carrot (Daucus carota L.) affects growth rather than sucrose partitioning. Plant Mol Biol. 1999;41(4):465-79.

63. Wormit A, Trentmann O, Feifer I, Lohr C, Tjaden J, Meyer S, Schmidt U, Martinoia E, Neuhaus HE. Molecular identification and physiological characterization of a novel monosaccharide transporter from Arabidopsis involved in vacuolar sugar transport. Plant Cell. 2006;18(12):3476-90.

64. Klann EM, Hall B, Bennett AB. Antisense acid invertase (TIV1) gene alters soluble sugar composition and size in transgenic tomato fruit. Plant Physiol. 1996;112(3):1321-30.

65. Davies C, Robinson SP. Sugar accumulation in grape berries. Cloning of two putative vacuolar invertase cDNAs and their expression in grapevine tissues. Plant Physiol 1996; 111(1): 275-283.

66. Greiner S, Rausch T, Sonnewald U, Herbers K. Ectopic expression of a tobacco invertase inhibitor homolog prevents cold-induced sweetening of potato tubers. Nat Biotechnol. 1999;17(7):708-11.

67. Bellin D, Schulz B, Soerensen TR, Salamini F, Schneider K. Transcript profiles at different growth stages and tap-root zones identify correlated developmental and metabolic pathways of sugar beet. J Exp Bot. 2007;58: 699-715.

68. Jones SI, Vodkin LO. Using RNA-Seq to profile soybean seed development from fertilization to maturity. PLoS One. 2013;8:e59270.

69. Sato $Y$, Takehisa H, Kamatsuki K, Minami H, Namiki N, Ikawa H, Ohyanagi H, Sugimoto K, Antonio BA, Nagamura Y. RiceXPro version 3.0: expanding the informatics resource for rice transcriptome. Nucleic Acids Res. 2013; 41 (Database issue):D1206-13.

70. Chen J, Zeng B, Zhang M, Xie S, Wang G, Hauck A, Lai J. Dynamic transcriptome landscape of maize embryo and endosperm development. Plant Physiol. 2014;166:252-64.

71. Huber SC, Huber JL. Role and regulation of sucrose-phosphate synthase in higher plants. Annu Rev Plant Physiol. 1996;47:431-44.

72. Winter $\mathrm{H}$, Huber SC. Regulation of sucrose metabolism in higher plants: localization and regulation of activity of key enzymes. CRC Crit Rev Plant Sci. 2000;19:31-67.

73. Chen S, Hajirezaei M, Peisker M, Tschiersch $H$, Sonnewald U, Börnke F. Decreased sucrose-6-phosphate phosphatase level in transgenic tobacco inhibits photosynthesis, alters carbohydrate partitioning, and reduces growth. Planta. 2005:221:479-92.

74. Lunn JE, MacRae E. New complexities in the synthesis of sucrose. Curr Opin Plant Biol. 2003;6:208-14

75. Castleden CK, Aoki N, Gillespie VJ, MacRae EA, Quick WP, Buchner P, Foyer $\mathrm{CH}$, Furbank RT, Lunn JE. Evolution and function of the sucrose-phosphate synthase gene families in wheat and other grasses. Plant Physiol. 2004;135: 1753-64.

76. Lutfiyya LL, Xu N, D'Ordine RL, Morrell JA, Miller PW, Duff SM. Phylogenetic and expression analysis of sucrose phosphate synthase isozymes in plants. J Plant Physiol. 2007;164(7):923-33.

77. Langenkamper G, Fung RWM, Newcomb RD, Atkinson RG, Gardner RC, MacRae EA. Sucrose phosphate synthase genes in plants belong to three different families. J Mol Evol. 2002;54:322-32.

78. Volkert K, Debast S, Voll LM, Voll H, SchießI I, Hofmann J, Schneider S, Börnke F. Loss of the two major leaf isoforms of sucrose-phosphate synthase in Arabidopsis thaliana limits sucrose synthesis and nocturnal starch degradation but does not alter carbon partitioning during photosynthesis. J Exp Bot. 2014;65(18):5217-29.

79. Lunn JE. Sucrose-phosphatase gene families in plants. Gene. 2003;303: 187-96.

80. Albi T, Ruiz MT, de Los Reyes P, Valverde F, Romero JM. Characterization of the sucrose phosphate phosphatase (SPP) isoforms from Arabidopsis thaliana and role of the S6PPC domain in dimerization. PLoS One. 2016; 11(11):e0166308.

81. Morris DL. Quantitative determination of carbohydrates with Dreywood's anthrone reagent. Science. 1948;107:254-5.

82. Miller GL. Use of dinitrosalicylic acid reagent for determination of reducing sugar. Anal Chem. 1959;31:426-8

83. Trapnell C, Williams BA, Pertea G, Mortazavi A, Kwan G, van Baren MJ, Salzberg SL, Wold BJ, Pachter L. Transcript assembly and quantification by RNA-Seq reveals unannotated transcripts and isoform switching during cell differentiation. Nat Biotechnol. 2010;28(5):511-5.
84. Schmittgen TD, Livak KJ. Analyzing real-time PCR data by the comparative C(T) method. Nat Protoc. 2008:3:1101-8.

85. Liu J, Deng S, Wang H, Ye J, Wu HW, Sun HX, Chua NH. CURLY LEAF regulates gene sets coordinating seed size and lipid biosynthesis. Plant Physiol. 2016;171:424-36

86. Troncoso-Ponce MA, Kilaru A, Cao X, Durrett TP, Fan J, Jensen JK, Thrower NA, Pauly M, Wilkerson C, Ohlrogge JB. Comparative deep transcriptional profiling of four developing oilseeds. Plant J. 2011;68:1014-27.

87. Bourgis F, Kilaru A, Cao X, Ngando-Ebongue GF, Drira N, Ohlrogge JB, Arondel $V$. Comparative transcriptome and metabolite analysis of oil palm and date palm mesocarp that differ dramatically in carbon partitioning. Proc Natl Acad Sci U S A. 2011;108:12527-32.

88. Kilaru A, Cao X, Dabbs PB, Sung HJ, Rahman MM, Thrower N, Zynda G, Podicheti R, Ibarra-Laclette E, Herrera-Estrella L, Mockaitis K, Ohlrogge JB. Oil biosynthesis in a basal angiosperm: transcriptome analysis of Persea Americana mesocarp. BMC Plant Biol. 2015;15:203.

89. Zenoni S, Ferrarini A, Giacomelli E, Xumerle L, Fasoli M, Malerba G, Bellin D, Pezzotti M, Delledonne M. Characterization of transcriptional complexity during berry development in Vitis vinifera using RNA-Seq. Plant Physiol. 2010;152(4):1787-95.

90. Norton G, Harris JF. Compositional changes in developing rape seed (Brassica napus L.). Planta. 1975;123:163-74.

91. Onyia VN, Offiah FU, Eze El, Ilo GE, Onwubiko NC. Proximate and mineral composition of some Nigerian castor (Ricinus communis) accessions. Acad J Biotech. 2015;3:093-6.

92. USDA National Nutrient Database for Standard Reference. Agricultural Research Service, U.S. Department of Agriculture. 2017. http://ndb.nal.usda. gov/ndb/nutrients/. Accessed 18 March 2017.

93. Olayiwola IO, Abubakar HN, Adebayo GB, Oladipo FO. Study of sweet potato (Ipomea batatas lam) foods for indigenous consumption through chemical and anti-nutritive analysis in Kwara state, Nigeria. Pak J Nutr. 2009; 8:1894-7.

94. Lombardo S, Pandino G, Mauromicale G. Nutritional and sensory characteristics of "early" potato cultivars under organic and conventiona cultivation systems. Food Chem. 2011:133:1249-54.

95. Mokady S, Dolev A. Nutritional evaluation of tubers of Cyperus esculentus L. J Sci Food Agric. 1970;21:211-4.

\section{Ready to submit your research? Choose BMC and benefit from:}

- fast, convenient online submission

- thorough peer review by experienced researchers in your field

- rapid publication on acceptance

- support for research data, including large and complex data types

- gold Open Access which fosters wider collaboration and increased citations

- maximum visibility for your research: over $100 \mathrm{M}$ website views per year

At BMC, research is always in progress.

Learn more biomedcentral.com/submissions 